\title{
Decay of ${ }^{185} \mathrm{TI},{ }^{185 m+g} \mathrm{Hg},{ }^{189 m+g} \mathrm{~Pb}$ and energy location of the $13 / 2^{+}$isomeric states in ${ }^{185} \mathrm{Hg},{ }^{189} \mathrm{~Pb},{ }^{193} \mathrm{Po}$ and ${ }^{197} \mathrm{Rn}$
}

\author{
J. Sauvage ${ }^{1, a}$, B. Roussière ${ }^{1}$, J. Genevey ${ }^{2}$, S. Franchoo ${ }^{1}$, A.N. Andreyev ${ }^{3}$, N. Barré ${ }^{1}$, A. Ben Braham ${ }^{4}$, C. \\ Bourgeois $^{1}$, J.-F. Clavelin ${ }^{1}$, H. De Witte ${ }^{5}$, D.V. Fedorov ${ }^{6}$, V.N. Fedoseyev ${ }^{7}$, L.M. Fraile ${ }^{8}$, X. Grave ${ }^{1}$, G. Huber ${ }^{9}$, \\ M. Huyse ${ }^{5}$, P. Kilcher ${ }^{1}$, U. Köster ${ }^{10}$, P. Kunz ${ }^{11}$, S.R. Lesher ${ }^{12}$, B.A. Marsh ${ }^{7}$, I. Mukha ${ }^{5}$, J. Oms ${ }^{1}$, M.G. Porquet ${ }^{13}$, \\ M. Seliverstov ${ }^{6,9}$, I. Stefanescu ${ }^{14}$, K. Van de Vel ${ }^{5}$, P. Van Duppen ${ }^{5}$, YU.M. Volkov ${ }^{6}$, and A. Wojtasiewicz ${ }^{15}$ \\ 1 Institut de Physique Nucléaire, IN2P3-CNRS/Université Paris-Sud, F-91406 Orsay Cedex, France \\ 2 Laboratoire de Physique Subatomique et de Cosmologie, IN2P3-CNRS/Université Joseph Fourier, F-38026 Grenoble Cedex, \\ France \\ 3 Department of Physics, University of York, York, YO10 5DD, UK \\ 4 Faculté des sciences de Tunis, 1060 le Belvédère, Tunis, Tunisia \\ 5 Instituut voor Kern- en Stralingsfysica, K.U. Leuven, B-3001 Leuven, Belgium \\ 6 Petersburg Nuclear Physics Institute, 188350, Gatchina, Russia \\ 7 ISOLDE, CERN, CH-1211 Genève 23, Switzerland \\ 8 Grupo de Física Nuclear, Universidad Complutense, CEI Moncloa, 28040 Madrid, Spain \\ ${ }^{9}$ Institut für Physik, Johannes Gutenberg Universität, D-55099 Mainz, Germany \\ 10 Institut Laue-Langevin, F-38042 Grenoble Cedex 9, France \\ 11 TRIUMF, Vancouver BC, V6T 2A3, Canada \\ 12 University of Wisconsin-La Crosse, La Crosse, WI 54601, USA \\ 13 Centre de Sciences Nucléaires et de Sciences de la Matière, F-91405 Orsay, France \\ 14 Forschungs-Neutronenquelle Heinz Maier-Leibnitz, Technische Universität München, D-85748 Garching, Germany \\ 15 Institute of Experimental Physics, University of Warsaw, Warsaw, Poland
}

Received: 17 December 2012 / Revised: 5 July 2013

Published online: 6 September 2013

(c) The Author(s) 2013. This article is published with open access at Springerlink.com

Communicated by J. Äystö

\begin{abstract}
The $\beta^{+} / \mathrm{EC}$ decay of ${ }^{185} \mathrm{Tl}$ was studied at the ISOLDE facility, the $\gamma$-rays belonging to ${ }^{185} \mathrm{Hg}$ have been identified and a partial low-spin level scheme of ${ }^{185} \mathrm{Hg}$ has been built. The decay of ${ }^{185 \mathrm{~m}+\mathrm{g}} \mathrm{Hg}$ was studied at the ISOCELE facility. Conversion electron lines of very low-energy transitions were observed for the first time. Electron data have been obtained for four transitions in ${ }^{185} \mathrm{Au}$ and two transitions in ${ }^{185} \mathrm{Hg}$. From the analysis performed using an internal energy calibration procedure the energy location of the ${ }^{185 \mathrm{~m}} \mathrm{Hg}$ has been determined to be $E_{\mathrm{IS}}=103.7(4) \mathrm{keV}$. This $E_{\mathrm{IS}}$ value is consistent with that determined independently, $E_{\mathrm{IS}}=94(13) \mathrm{keV}$, using ${ }^{185 \mathrm{~m}+\mathrm{g}} \mathrm{Hg} \alpha$-decay data from literature. New $\alpha$ particles emitted from ${ }^{189 \mathrm{~m}+\mathrm{g}} \mathrm{Pb}$ have been detected and their origins determined by in-source laser spectroscopy at the ISOLDE facility. $\alpha-\gamma$ coincidence results have served to locate the $13 / 2^{+}$isomeric state of ${ }^{189} \mathrm{~Pb}$ at $E_{\mathrm{IS}}=40(4) \mathrm{keV}$. This latter $E_{\mathrm{IS}}$ value added to $\alpha$-decay data from literature have allowed the energy location of the $13 / 2^{+}$isomeric states of ${ }^{193} \mathrm{Po}$ and ${ }^{197} \mathrm{Rn}$ at $95(7) \mathrm{keV}$ and $194(12) \mathrm{keV}$, respectively. The nuclear structure of the isomeric and ground states in the nuclei of the three $\alpha$-emitter chains starting with $195 \mathrm{~m}+\mathrm{g}, 197 \mathrm{~m}+\mathrm{g}, 199 \mathrm{~m}+\mathrm{g} \mathrm{Rn}$ are discussed.
\end{abstract}

\section{Introduction}

Atomic and nuclear spectroscopy studies have revealed great nuclear-shape instability for the neutron-deficient $\mathrm{Hg}, \mathrm{Au}, \mathrm{Pt}$ and Ir nuclei situated far from the valley of stability. For these elements, states corresponding to a rather large nuclear deformation appear suddenly for a

\footnotetext{
${ }^{a}$ e-mail: sauvage@ipno.in2p3.fr
}

mass number $A<187$ [1-7], giving rise to shape or deformation change between neighbouring isotopes and/or to coexistence of states having different nuclear shapes or deformations in one nucleus. The most spectacular examples of shape coexistence have been discovered in the ${ }^{185,186} \mathrm{Hg}$ nuclei where states corresponding to very different deformation parameters, $|\beta|=0.15$ and $|\beta|=0.25$, coexist at low excitation energy $[1,2]$. These phenomena 
caused a large interest and numerous experimental and theoretical works have been performed [8-10]. In recent years, the deformation evolution of the neutron-deficient ${ }^{182-190} \mathrm{~Pb}$ nuclei was investigated by in-source laser spectroscopy. The changes in nuclear charge radius and the nuclear-moment values have already been published [11, 12]. These results have shown that the $\mathrm{Pb}$ nuclei in their isomeric and ground states keep a quasi-spherical shape even far from the valley of stability. New $\alpha$ particles emitted from the ${ }^{189 \mathrm{~m}+\mathrm{g}} \mathrm{Pb}$ nucleus have been detected during the latter experiment. They can serve to determine the energy location of the $13 / 2^{+}$isomeric state of the ${ }^{189} \mathrm{~Pb}$ nucleus provided the energy of the $13 / 2^{+}$isomeric state of ${ }^{185} \mathrm{Hg}$ is unambiguously established and $\gamma$-rays belonging to ${ }^{185} \mathrm{Hg}$ are known and located in the ${ }^{185} \mathrm{Hg}$ level scheme.

In this paper we report on the results obtained from three different experiments. The whole of the results have been used to determine a new or improved value of the energy location of the $13 / 2^{+}$isomeric state relative to the ground state in ${ }^{185} \mathrm{Hg},{ }^{189} \mathrm{~Pb},{ }^{193} \mathrm{Po}$ and ${ }^{197} \mathrm{Rn}$.

To identify the $\gamma$-rays belonging to the ${ }^{185} \mathrm{Hg}$ nucleus and build a low-energy low-spin level scheme of ${ }^{185} \mathrm{Hg}$, a new study of the $\beta^{+} / \mathrm{EC}$ decay of the ${ }^{185} \mathrm{Tl}$ nucleus has been performed, the experimental procedure and the results will be presented in sect. 2 .

The decay of ${ }^{185 \mathrm{~m}+\mathrm{g}} \mathrm{Hg}$ was studied by use of a Very Low-Energy Conversion Electron Detection, VLECED, setup [13]. The preliminary results of this experiment were reported in a conference only [14]. The high energy resolution electron spectrum recorded in this experiment has been carefully analysed using an internal calibration procedure, the experimental procedure will be briefly described and the results will be given in sect. 3. Moreover, by combining known $\alpha$-decay properties of ${ }^{185 \mathrm{~m}+\mathrm{g}} \mathrm{Hg}$ [15] and energy levels in ${ }^{181} \mathrm{Pt}[16,17]$, an independent value for the excitation energy of the ${ }^{185} \mathrm{Hg}$ isomer has been determined, the result will be also presented in sect. 3 .

After a short description of the experiment performed to detect and identify the $\alpha$ particles emitted from the $189 \mathrm{~m}+\mathrm{g} \mathrm{Pb}$ nucleus, the results that have served to determine the energy location of the isomeric state in ${ }^{189} \mathrm{~Pb}$, ${ }^{193} \mathrm{Po}$ and ${ }^{197} \mathrm{Rn}$ will be presented in sect. 4 .

In sect. 5, the nuclear data and structures that are well established for the nuclei situated in the neighbourhood of ${ }^{185} \mathrm{Hg}$ and ${ }^{189} \mathrm{~Pb}$ will be recalled very briefly, our results on the $\alpha$-emitter chain starting with ${ }^{197 m+g} \mathrm{Rn}$ will be compared with those known on the $\alpha$-emitter chains starting with ${ }^{195 m+g} \mathrm{Rn}$ and ${ }^{199 m+g} \mathrm{Rn}$ and then, the nuclear structure of the isomeric and ground states of the nuclei of these three chains will be discussed.

\section{Low-energy levels of ${ }^{185} \mathrm{Hg}$ from $\beta^{+} / \mathrm{EC}$ decay of ${ }^{185} \mathrm{TI}$}

\subsection{Experimental procedure}

The experiment was realized at the ISOLDE facility [18] at CERN. Radioactive atoms were produced by bombarding a thick uranium-carbide, $\mathrm{UC}_{\mathrm{x}}$, target with the

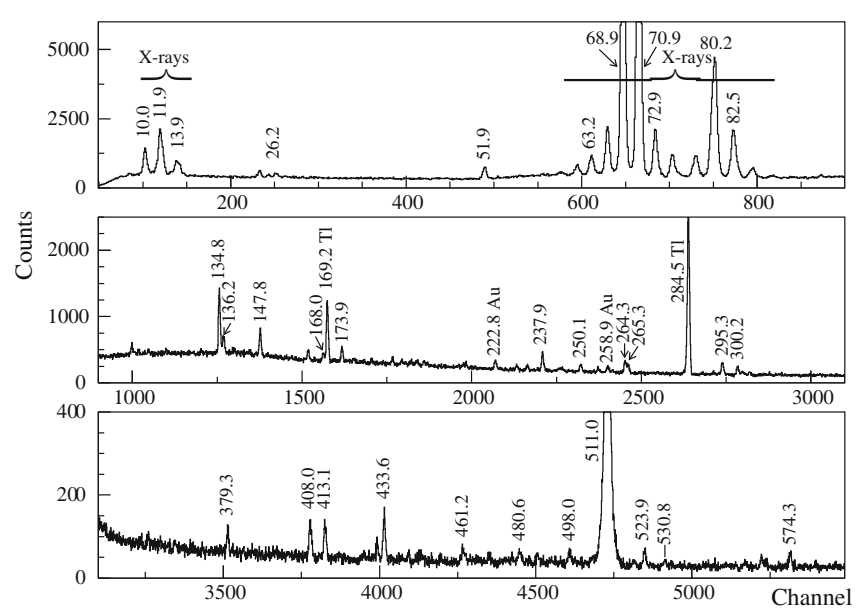

Fig. 1. Low-energy singles $\gamma$-ray spectrum obtained with the planar $\mathrm{Ge}(\mathrm{HP}) \mathrm{X}$-ray detector. The $\gamma$-ray energies are given in $\mathrm{keV}$.

1.4 GeV protons delivered by the PS-Booster. The radioactive atoms released from the target effuse into a hot cavity where the $\mathrm{Tl}$ atoms are easily surface ionized. The ions were extracted using a high voltage of $60 \mathrm{kV}$ and mass-separated by the General Purpose Separator, GPS. The mass-separated ion beam was then guided to a counting station, collected into a tape and, using the ISOLDE tape transport system, the obtained radioactive source was moved in front of three $\gamma$-ray detectors: one planar $\mathrm{Ge}(\mathrm{HP})$ X-ray detector with a $0.55 \mathrm{keV}$ FWHM resolution at $80 \mathrm{keV}$ and $0.9 \mathrm{keV}$ at $356 \mathrm{keV}$, and two coaxial $\mathrm{Ge}(\mathrm{HP})$ detectors with about $70 \%$ relative efficiency and $2.5,2.9 \mathrm{keV}$ FWHM resolution at $1.33 \mathrm{MeV}$. Twenty milliseconds after a proton pulse hit the target, the radioactive ion beam was collected into the tape for a collecting time, $t_{\mathrm{c}}=2 \mathrm{~s}$, then, after the source transport time, $t_{\mathrm{t}}=1.5 \mathrm{~s}$, the $\gamma$-rays and X-rays from the source were counted for a measuring time, $t_{\mathrm{m}}=15.3 \mathrm{~s}$. This time cycle was repeated for 3 hours.

The data were treated using a COMET-NARVAL acquisition system [19-21]. For each detected radiation the energy and absolute time were encoded by the COMET card. The NARVAL software served to associate energy and absolute time to create an event, to build on-line singles and coincidence control spectra and to send all information to be recorded on disk. From the recorded information, the coincidence events were built again off-line and sorted to get $\gamma-\gamma-t$ and $\gamma$-X- $t$ coincidence matrices.

\subsection{Results}

The singles $\gamma$-ray spectrum obtained with the X-ray detector is shown in fig. 1 . The main $\gamma$-rays coincident with the X-rays are listed in table 1 . The energy, intensity, main coincident $\gamma$-rays and location in the level scheme of the $\gamma$-rays belonging to the $\beta^{+} / \mathrm{EC}$ decay of the ${ }^{185} \mathrm{Tl}$ nucleus are given in table 2 .

${ }^{185} \mathrm{Tl}$ is produced in both the $9 / 2^{-}$isomeric and $1 / 2^{+}$ ground states that partly decay by $\alpha$-particle emission. 
Table 1. X-ray data for the ${ }^{185} \mathrm{Tl}$ decay. X-ray intensities are given relatively to the ${ }^{185 \mathrm{~m}} \mathrm{Tl}$ isomeric transition, $284.5 \mathrm{keV}$ $\left(I_{\gamma}=1000\right)$. Parentheses mean uncertain coincidence relationship.

\begin{tabular}{|c|c|c|c|}
\hline$E(\mathrm{keV})^{(\mathrm{a})}$ & $I^{(\mathrm{b})}$ & & Main coincident $\gamma$-rays \\
\hline 10.0 & 43 & $\mathrm{XHg}$ & \\
\hline 10.3 & 20 & $\mathrm{XTl}$ & \\
\hline 11.5 & 16 & $\mathrm{XAu}$ & \\
\hline 11.9 & 78 & $\mathrm{XHg}$ & \\
\hline 12.3 & 37 & $\mathrm{XTl}$ & \\
\hline 13.9 & 26 & $\mathrm{XHg}$ & \\
\hline 14.3 & 21 & $\mathrm{XTl}+\mathrm{XHg}$ & \\
\hline 24.2 & 11 & $(\mathrm{XIn})$ & \\
\hline 63.2 & 19 & XIr & \\
\hline 65.0 & 33 & $\mathrm{XPt}+\mathrm{XIr}$ & $230^{(\mathrm{d})}$ \\
\hline 67.0 & 80 & $\mathrm{XAu}+\mathrm{XPt}$ & $223^{(\mathrm{e})}, 244^{(\mathrm{e})}, 259^{(\mathrm{e})}$ \\
\hline 68.9 & 550 & $\mathrm{XHg}+\mathrm{XAu}$ & $135,148,163,223^{(\mathrm{e})}, 238,265,300,408,434,674$ \\
\hline 70.9 & 803 & $\mathrm{XHg}+\mathrm{XTl}$ & $\begin{array}{l}135,148,163,168,(174), 213,238,265,(293), 295,300,(302),(336), 379,408, \\
413,431,434,461,(481),(498),(524),(531),(566), 630,(695),(804), 2099\end{array}$ \\
\hline 72.9 & 80 & $\mathrm{XTl}+\mathrm{XPb}$ & $169.2^{(\mathrm{f})}, 284.5^{(\mathrm{f})}$ \\
\hline 73.4 & 8 & XIr & \\
\hline 75.0 & 43 & $\mathrm{XPb}+\mathrm{XPt}+\mathrm{XIr}$ & \\
\hline 77.9 & 41 & $\mathrm{XAu}+\mathrm{XPt}$ & $190^{(\mathrm{e})},(259)^{(\mathrm{e})}$ \\
\hline $80.2^{(\mathrm{c})}$ & 273 & $\mathrm{XHg}+\mathrm{XAu}$ & $135,(168), 174,238,265,408,434,524$ \\
\hline 82.5 & 89 & $\mathrm{XTl}+\mathrm{XHg}$ & 135 \\
\hline 83.0 & 17 & $\mathrm{XTl}+\mathrm{XHg}$ & \\
\hline 84.8 & 21 & $\mathrm{XTl}+\mathrm{XPb}$ & \\
\hline
\end{tabular}

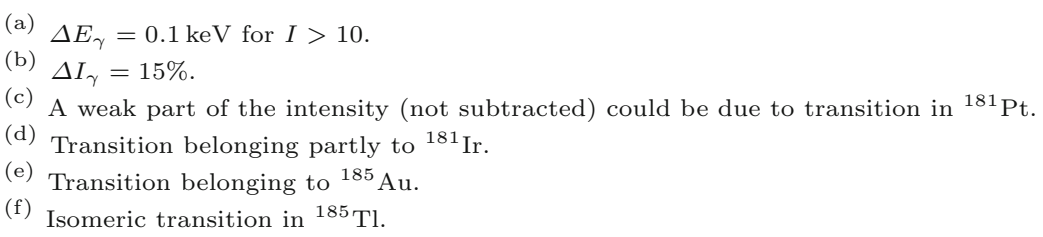

Their ${ }^{185} \mathrm{Hg}$ and ${ }^{181} \mathrm{Au}$ daughters and ${ }^{185} \mathrm{Au},{ }^{185} \mathrm{Pt},{ }^{181} \mathrm{Au}$ and ${ }^{181} \mathrm{Pt}$ granddaughters decay also by $\alpha$ and $\beta^{+} / \mathrm{EC}$ process. This results in complex $\gamma$-ray spectra in which $\gamma$-rays belonging to ${ }^{181} \mathrm{Au},{ }^{181} \mathrm{Pt},{ }^{181} \mathrm{Ir}$ and ${ }^{177} \mathrm{Os}$ are expected to be present in spite of the mass separation. These $\gamma$-rays have been identified from known data and/or their observation in coincidence with X-rays (see table 1).

The $169.2 \mathrm{keV}\left(I_{\gamma}=128\right)$ and $284.5 \mathrm{keV}\left(I_{\gamma}=1000\right)$ $\gamma$-rays observed with the strongest intensities (see fig. 1 ) are the isomeric transitions that de-excite the $9 / 2^{-185} \mathrm{Tl}$ isomeric state towards the $1 / 2^{+185} \mathrm{Tl}$ ground state. Their properties are in good agreement with those reported in the literature [22].

The $190.0 \mathrm{keV}\left(I_{\gamma}=10\right), 222.8 \mathrm{keV}\left(I_{\gamma}=28\right)$, $243.6 \mathrm{keV}\left(I_{\gamma}=17\right), 258.9 \mathrm{keV}\left(I_{\gamma}=28\right) \gamma$-rays observed coincident with the Au X-rays belong to the $\beta^{+} / \mathrm{EC}$ decay of the $1 / 2^{-}{ }^{185} \mathrm{Hg}$ ground state whereas no $\gamma$-ray of the $\beta^{+} / \mathrm{EC}$ decay of the $13 / 2^{+}{ }^{185} \mathrm{Hg}$ isomeric state is observed (see table 1 ). This confirms that the $9 / 2^{-}{ }^{185} \mathrm{Tl}$ isomeric state decays by isomeric transitions and $\alpha$ particles only.

A $309.5 \mathrm{keV}\left(I_{\gamma}=8\right) \gamma$-ray is also observed, it is a doublet composed of the $309.0 \mathrm{keV}$ and $310.4 \mathrm{keV} \gamma$-rays that represents $16.6 \%$, from ref. [23], of the ${ }^{185} \mathrm{Au} \beta^{+} / \mathrm{EC}$ decay.

Two $\gamma$-rays with weak intensities: $94.0 \mathrm{keV}\left(I_{\gamma} \sim 7\right)$ and $198.0 \mathrm{keV}\left(I_{\gamma}=8\right)$, correspond to transitions in ${ }^{181} \mathrm{Pt}$. The $\alpha$ decay of the $1 / 2^{-185} \mathrm{Hg}$ ground state does not feed the $7 / 2^{-}$state located at $278.2 \mathrm{keV}$ in the ${ }^{181} \mathrm{Pt}$ nucleus. Thus, the $198.0 \mathrm{keV} \gamma$-ray is only due to the ${ }^{181} \mathrm{Au} \beta^{+} / \mathrm{EC}$ decay and represents $4.42 \%$, from ref. [23], of this decay.

The $229.7 \mathrm{keV}\left(I_{\gamma}=17\right) \gamma$ line observed coincident with the Ir X-rays belongs, at least partly, to the $\beta^{+} / \mathrm{EC}$ decay of the ${ }^{181} \mathrm{Pt}$ nuclei produced from both the ${ }^{181} \mathrm{Au}$ $\beta^{+} / \mathrm{EC}$ decay and ${ }^{185 \mathrm{~g}} \mathrm{Hg} \alpha$ decay.

A partial level scheme, in three separate parts, of the ${ }^{185} \mathrm{Hg}$ nucleus (A, B and $\mathrm{C}$ shown in fig. 2) could be built from the data listed in table 2. Part A includes the $26 \mathrm{keV}$ transition known to de-excite the first $3 / 2^{-}$excited state towards the $1 / 2^{-}{ }^{185} \mathrm{Hg}$ ground state [24]. It consists mainly of three couples of transitions having an energy difference of $\Delta E=26.0(1) \mathrm{keV}$, namely: 147.8 $173.9,413.1-439.1$ and $498-523.9 \mathrm{keV}$. A percentage of $21 \%$ of the total $\gamma$ intensity $\left(I_{\gamma \text { tot }}=1800\right)$ reported in table 2 has been located in this part of the level scheme. Part B consists of five transitions corresponding to $6 \%$ of 
Table 2. $\gamma$-ray data for the $\beta^{+} / \mathrm{EC}$ decay of the ${ }^{185} \mathrm{Tl}$ ground state. $\gamma$-line intensities are given relatively to the ${ }^{185 \mathrm{~m}} \mathrm{Tl}$ isomeric transition, $284.5 \mathrm{keV}\left(I_{\gamma}=1000\right)$. Parentheses mean uncertain coincidence relationship or tentative location.

\begin{tabular}{|c|c|c|c|}
\hline$E(\mathrm{keV})^{(\mathrm{a})}$ & $I^{(\mathrm{b})}$ & Main coincident $\gamma$-rays & Location \\
\hline 26.2 & 8 & & $26.0 \rightarrow 0$ \\
\hline 51.9 & 19 & $\mathrm{XHg}$ & \\
\hline 134.8 & 81 & $\mathrm{XHg}, 238,434,(481,520), 531$ & $134.8+x \rightarrow x$ \\
\hline 136.2 & 18 & $\mathrm{XHg}$ & $136.2+y \rightarrow y$ \\
\hline 147.8 & 47 & $\mathrm{XHg}, 265,(461)$ & $173.9 \rightarrow 26.0$ \\
\hline 163.1 & 25 & $\mathrm{XHg}$ & \\
\hline 168.0 & 24 & 136,487 & $304.1+y \rightarrow 136.2+y$ \\
\hline 173.9 & 33 & $\mathrm{XHg}$ & $173.9 \rightarrow 0$ \\
\hline 212.8 & 22 & $(\mathrm{XHg})$ & \\
\hline 237.9 & 69 & $\mathrm{XHg}, 135,531,(661,674,739)$ & $372.7+x \rightarrow 134.8+x$ \\
\hline $250.1^{(\mathrm{c})}$ & 18 & $(\mathrm{XHg})$ & \\
\hline 264.3 & 61 & $\mathrm{XHg}, 484$ & \\
\hline 265.3 & 44 & $\mathrm{XHg}, 148,(174)$ & $439.2 \rightarrow 173.9$ \\
\hline 292.7 & 20 & $\mathrm{XHg},(168,304)$ & $596.8+y \rightarrow 304.1+y$ \\
\hline 295.3 & 87 & $\mathrm{XHg}, 379$ & \\
\hline 300.2 & 52 & $\mathrm{XHg},(470,520)$ & \\
\hline 301.7 & 25 & & \\
\hline 304.0 & 22 & $(293), 487$ & $304.1+y \rightarrow y$ \\
\hline $335.7^{(\mathrm{c})}$ & 14 & (XHg), (434) & $903.8+x \rightarrow 568.4+x$ \\
\hline 379.3 & 29 & $\mathrm{XHg}$ & \\
\hline 408.0 & 79 & $\mathrm{XHg}$ & \\
\hline 413.1 & 79 & $\mathrm{XHg}$ & $(439.2 \rightarrow 26.0)$ \\
\hline $431.1^{(\mathrm{c})(\mathrm{d})}$ & 31 & $(\mathrm{XHg})$ & \\
\hline 433.6 & 103 & $\mathrm{XHg}, 135,336,(481,520)$ & $568.4+x \rightarrow 134.8+x$ \\
\hline 439.1 & 11 & & $(439.2 \rightarrow 0)$ \\
\hline 453.1 & 15 & 566 & \\
\hline 461.2 & 50 & $\mathrm{XHg}$ & \\
\hline 465.6 & 12 & & $(1033.9+x \rightarrow 568.4+x)$ \\
\hline 469.9 & 18 & $(300)$ & \\
\hline 478 & & $(434)$ & $(1046.8+x \rightarrow 568.4+x)$ \\
\hline $480.6^{(\mathrm{c})(\mathrm{d})}$ & 34 & XHg, 434, (498) & $1049.0+x \rightarrow 568.4+x$ \\
\hline 483.7 & 7 & 264 & \\
\hline 486.8 & 22 & XHg, (168), 304 & $790.9+y \rightarrow 304.1+y$ \\
\hline 498.0 & 39 & $(624)$ & $(524.0 \rightarrow 26.0)$ \\
\hline 519.8 & 30 & $\mathrm{XHg},(135,300), 434$ & $1088.2+x \rightarrow 568.4+x$ \\
\hline 523.9 & 65 & $\mathrm{XHg}, 624$ & $524.0 \rightarrow 0$ \\
\hline 530.8 & 26 & $(\mathrm{XHg}), 135,238$ & $903.8+x \rightarrow 372.7+x$ \\
\hline 564.5 & 42 & $\mathrm{XHg}$ & \\
\hline 566.1 & 21 & 453 & \\
\hline 574.3 & 57 & $(\mathrm{XHg})$ & \\
\hline 624.4 & 17 & $\mathrm{XHg}, 524$ & $1148.4 \rightarrow 524.0$ \\
\hline 629.8 & 20 & $(148)$ & $(803.8 \rightarrow 173.9)$ \\
\hline $661.2^{(\mathrm{c})}$ & 20 & 238 & $1033.9+x \rightarrow 372.7+x$ \\
\hline 674.1 & 15 & 238 & $1046.8+x \rightarrow 372.7+x$ \\
\hline 695.1 & 36 & $\mathrm{XHg}$ & \\
\hline 738.5 & 8 & 238 & $1111.2+x \rightarrow 372.7+x$ \\
\hline 803.9 & 19 & & $(803.9 \longrightarrow 0)$ \\
\hline 1082.7 & 14 & $\mathrm{XHg},(461)$ & \\
\hline 1293.5 & 41 & & \\
\hline 1612.9 & 31 & $(413)$ & \\
\hline 1878.3 & 27 & & \\
\hline 2099.2 & 60 & & \\
\hline 2122.2 & 33 & & \\
\hline
\end{tabular}

(a) $\Delta E_{\gamma}=0.1 \mathrm{keV}$ for $E_{\gamma}<200 \mathrm{keV}, I>10,0.2 \mathrm{keV}$ for $200<E_{\gamma}<1500 \mathrm{keV}, 0.3 \mathrm{keV}$ for $E_{\gamma}>1500 \mathrm{keV}$.

(b) $\Delta I_{\gamma}=15 \%$.

(c) Intensities due to other decays have been subtracted.

(d) A weak part of the intensity (not subtracted) could be due to transition in ${ }^{181} \mathrm{Pt}$. 

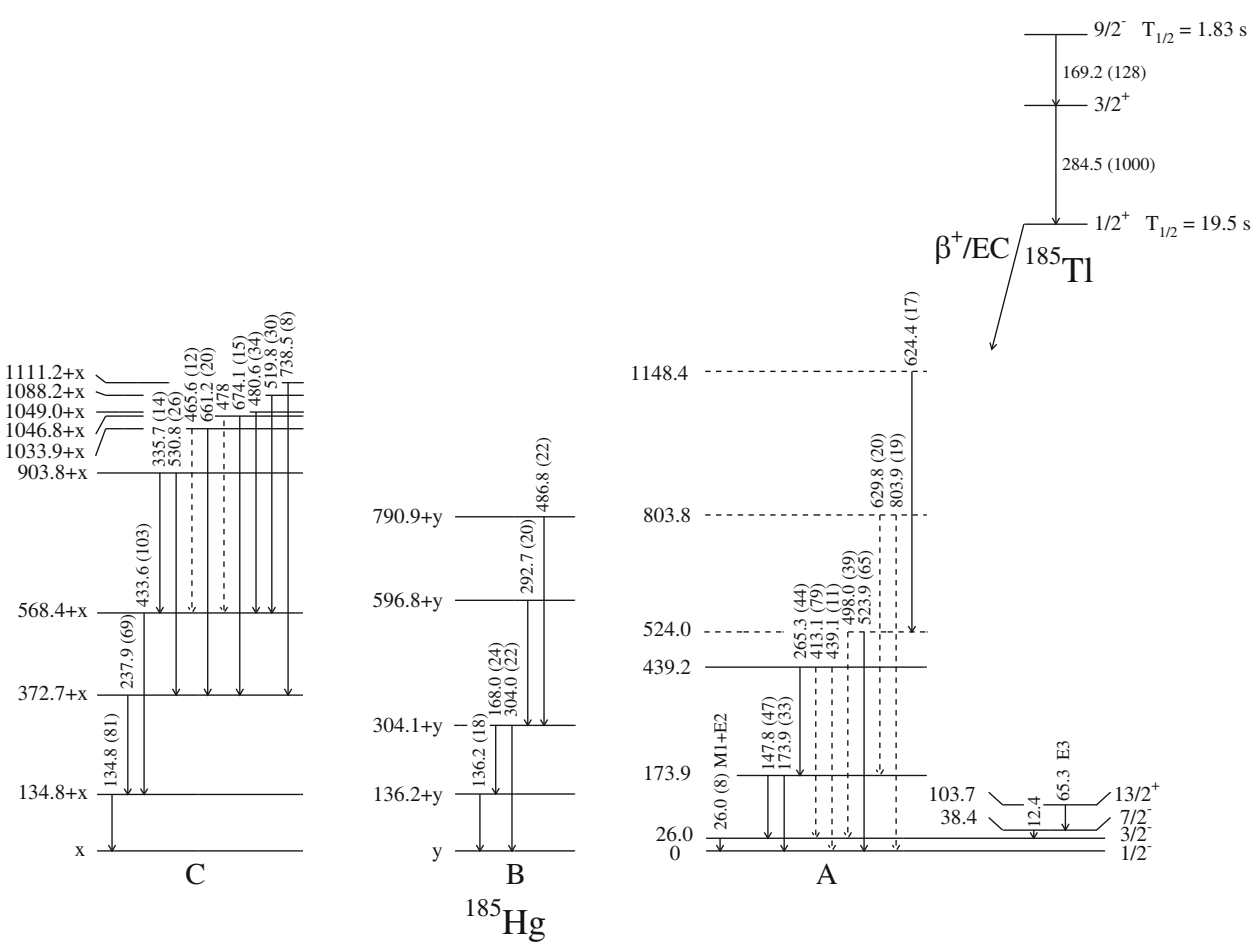

Fig. 2. Partial level scheme of ${ }^{185} \mathrm{Hg}$ obtained from the $\beta^{+} / \mathrm{EC}$ decay of the ${ }^{185} \mathrm{Tl}$ ground state. Parts $\mathrm{B}$ and $\mathrm{C}$ can be either on the $1 / 2^{-}$ground state or on top of the $3 / 2^{-}$state located at $26.0 \mathrm{keV}$. The decay of the ${ }^{185 \mathrm{~m}} \mathrm{Hg}$ by isomeric transitions is shown on the right-hand side though it is not fed from the $\beta^{+} / \mathrm{EC}$ decay of ${ }^{185} \mathrm{Tl}$ (see text).

the total $\gamma$ intensity. In part $\mathrm{C}$, twelve transitions that represent $23 \%$ of the total $\gamma$ intensity, have been placed. Though the $13 / 2^{+}$isomeric state of ${ }^{185} \mathrm{Hg}$ is not fed from the $\beta^{+} / \mathrm{EC}$ decay of ${ }^{185} \mathrm{Tl}$, its decay by isomeric transitions (obtained from ref. [24] and the results presented in sect. 3 ) is shown in fig. 2 on the right-hand side.

Only 26.2 and $51.9 \mathrm{keV} \gamma$-rays belonging to the ${ }^{185} \mathrm{Tl}$ $\beta^{+} / \mathrm{EC}$ decay have been observed in the $\gamma$ spectrum with energy smaller than $130 \mathrm{keV}$. The multipolarity of the $51.9 \mathrm{keV}$ transition is unknown, it may be $E 1$ or more probably $M 1$ or $M 1+E 2$, the total intensity of this transition may then vary from $I_{\text {tot }}=29$ for an $E 1, I_{\text {tot }}=210$ for an $M 1$, to $I_{\text {tot }}=2300$ for an $E 2$ transition. Three couples of transitions with energy difference of $51.7(2) \mathrm{keV}$ exist in table 2: 212.8-264.3, 250.1-301.7 and 379.3-431.1 keV but no coincidence relationship has allowed us to establish a partial level scheme including the $51.9 \mathrm{keV}$ transition. The multipolarity of the $26.02(10) \mathrm{keV}$ transition has been determined to be $M 1+(3.4(10) \%) E 2$ (see next section), the total intensity of this transition is then rather high, $I_{\text {tot }}=1550(270)$. The ${ }^{185} \mathrm{Tl}$ ground state has spin and parity values, $I^{\pi}=1 / 2^{+}$, it decays mainly to the $1 / 2^{-}$ and $3 / 2^{-}$states of ${ }^{185} \mathrm{Hg}$ since no $1 / 2^{+}$or $3 / 2^{+}$state is expected to be located at low energy in this nucleus. Thus, the $3 / 2^{-}$state located at $26.0 \mathrm{keV}$ in ${ }^{185} \mathrm{Hg}$ may be fed directly by the ${ }^{185} \mathrm{Tl} \beta^{+} / \mathrm{EC}$ decay, which is consistent with the large total intensity observed for the $26 \mathrm{keV}$ transition. From part A of the level scheme the sum of the total intensities of the transitions arriving on the ground state is at least equal to $1678(289)$. In addition to that sum, the $1 / 2^{-}$ground state of ${ }^{185} \mathrm{Hg}$ may also be fed directly by the ${ }^{185} \mathrm{Tl} \beta^{+} / \mathrm{EC}$ decay. This means that transitions as the $295.3 \mathrm{keV}$ that appears with high $\gamma$ intensity in table 2 actually represent only a small percentage $(<5 \%)$ of the ${ }^{185} \mathrm{Tl} \beta^{+} / \mathrm{EC}$ decay. We note that, from the $\gamma$ intensities measured, the $51.9 \mathrm{keV}$ transition (except for a pure $E 2$ multipolarity), part B and part $\mathrm{C}$ of the level scheme may be based either on the $26.0 \mathrm{keV}$ state or on the ground state.

\section{Low-energy transitions in ${ }^{185} \mathrm{Au}$ and ${ }^{185} \mathrm{Hg}$ from the ${ }^{185 m+g} \mathrm{Hg}$ decay}

\subsection{Experimental procedure}

A measurement of the low-energy conversion electrons emitted from ${ }^{185 \mathrm{~m}+\mathrm{g}} \mathrm{Hg}$ radioactive atoms were carried out using the VLECED system [13] that was installed at the ISOCELE facility [25]. Mercury atoms were produced by $(\mathrm{p}, x \mathrm{n})$ reactions on a molten gold target placed inside the ISOCELE mass separator ion source $[26,27]$. The $44 \mathrm{keV}$ radioactive mercury beam extracted from the ion source was mass separated, decelerated and focused before being deposited on a transport tape as a very narrow spot. After the source was moved inside a $180^{\circ}$ flat magnetic spectrograph, a high voltage of $-10 \mathrm{kV}$ was applied to it to accelerate the emitted electrons. Thus, the low-energy electrons could reach a photographic film and be detected. 


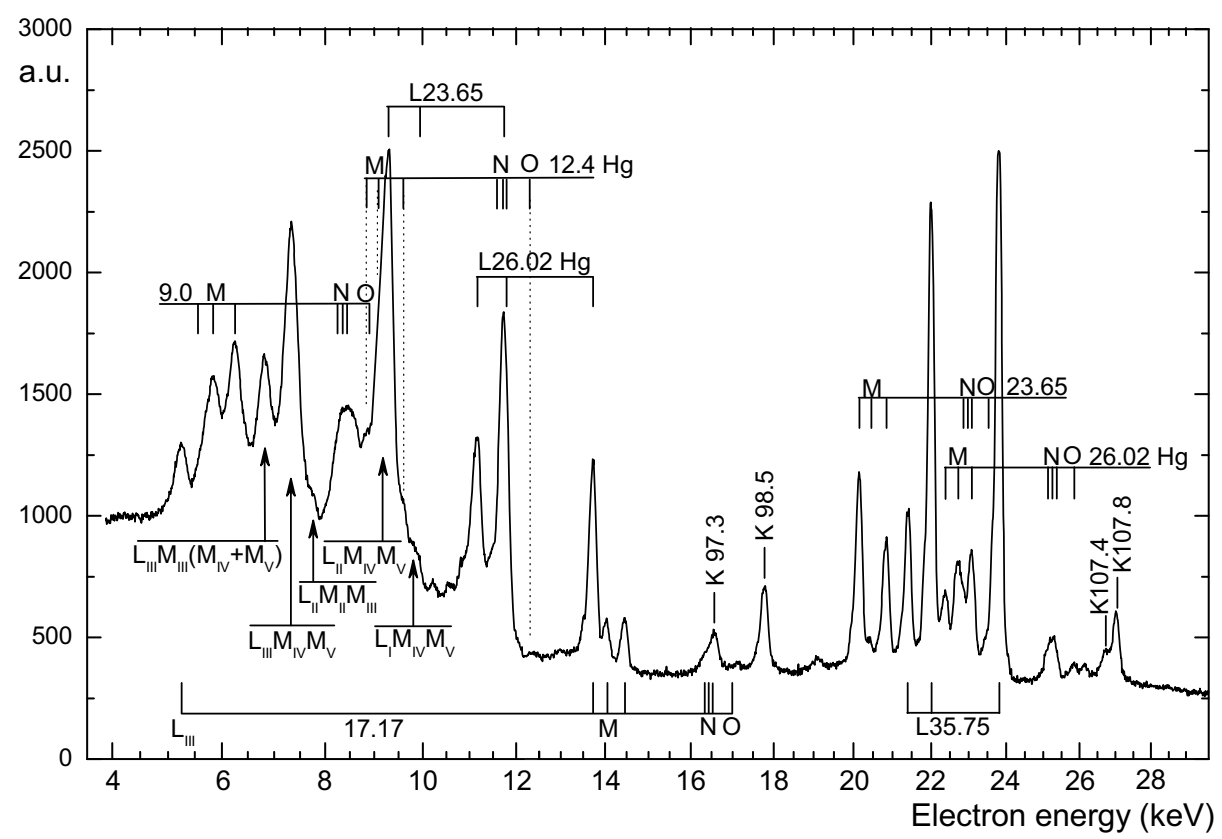

Fig. 3. Low-energy electron spectrum obtained for the ${ }^{185 \mathrm{~m}+\mathrm{g}} \mathrm{Hg}$ decay using the flat magnetic spectrograph with $B=5.10^{-3} \mathrm{~T}$ and $H . V .=-10 \mathrm{kV}$. The transition energies are given in $\mathrm{keV}$. The isomeric transitions in ${ }^{185} \mathrm{Hg}$ are marked with $\mathrm{Hg}$. The electron lines that served to the internal energy calibration are indicated below the spectrum.

A high energy resolution was obtained even for the lowenergy electrons thanks to the decelerating lens that preserved the quality of the beam focalisation and prevented too deep an implantation of the ions into the tape, for example, a resolution of $0.2 \mathrm{keV}$ FWHM has been obtained at an electron energy of $14.4 \mathrm{keV}$. The slowed ion beam was deposited for a collecting time, $t_{\mathrm{c}}=30 \mathrm{~s}$, and then the accelerated electrons detected for a measuring time, $t_{\mathrm{m}}=30 \mathrm{~s}$, this time cycle was repeated until the total measuring time was 4 hours. The energies obtained with the flat magnetic spectrograph are expected to be very precisely measured (typically $0.05 \mathrm{keV}$ ) by the electronline distance from notch positions used as geometric references. However, it has been shown that the high voltage applied to the electron source slightly modifies the electron trajectories in the spectrograph giving energy deviations for the electrons with energies smaller than $25 \mathrm{keV}$ [28].

\subsection{Results}

The low-energy part of the electron spectrum obtained with a magnetic induction of $5 \times 10^{-3} \mathrm{~T}$ is shown in fig. 3. The preliminary results obtained from this experiment were presented in a conference [14]. The $13 / 2^{+}$isomeric state was then located at $E_{\mathrm{IS}}=103.8 \mathrm{keV}$ above the $1 / 2^{-}$ground state of ${ }^{185} \mathrm{Hg}$. In a second step, a careful analysis of the electron spectrum has been performed using an internal energy calibration procedure. The numerous LMM, LMN and LMO Auger electron lines of $\mathrm{Au}$ and $\mathrm{Hg}$ atoms have energies between 5 and $13 \mathrm{keV}$. They are observed in the part of interest of the electron spectrum. An Auger electron spectrum has been built from the calculated energies and intensities $[29,30]$ of the 125, for $\mathrm{Au}$, and 129, for $\mathrm{Hg}$, main LMM, LMN and LMO Auger electron lines. The comparison of the calculated $(80 \% \mathrm{Au}+20 \% \mathrm{Hg})$ Auger electron spectrum with the experimental ones has allowed us to unambiguously identify the $6.87 \mathrm{keV}\left(\mathrm{L}_{\mathrm{III}} \mathrm{M}_{\mathrm{III}} \mathrm{M}_{\mathrm{IV}}+\mathrm{L}_{\mathrm{III}} \mathrm{M}_{\mathrm{III}} \mathrm{M}_{\mathrm{V}}\right)$, $7.35 \mathrm{keV}\left(\mathrm{L}_{\mathrm{III}} \mathrm{M}_{\mathrm{IV}} \mathrm{M}_{\mathrm{V}}\right), 7.79 \mathrm{keV}\left(\mathrm{L}_{\mathrm{II}} \mathrm{M}_{\mathrm{II}} \mathrm{M}_{\mathrm{III}}\right), 9.17 \mathrm{keV}$ $\left(\mathrm{L}_{\mathrm{II}} \mathrm{M}_{\mathrm{IV}} \mathrm{M}_{\mathrm{V}}\right)$ and $9.78 \mathrm{keV}\left(\mathrm{L}_{\mathrm{I}} \mathrm{M}_{\mathrm{IV}} \mathrm{M}_{\mathrm{V}}\right) \mathrm{Au}$ Auger electron lines. In addition to this, some transition energies belonging to ${ }^{185} \mathrm{Au}$ had been precisely determined using the same spectrograph but without high voltage applied to the source [24], conversion electron lines of two of them, also observed in the spectrum, served the internal energy calibration: namely $\mathrm{L}_{\mathrm{III}}, \mathrm{M}_{\mathrm{III}}$ conversion electron lines of the $17.17(3) \mathrm{keV}$ transition and $\mathrm{L}_{\mathrm{I}}, \mathrm{L}_{\mathrm{II}}, \mathrm{L}_{\mathrm{III}}$ lines of the $35.75(5) \mathrm{keV}$ transition. The electron energies, $E_{\text {electron, }}$ electron intensities, $I_{\mathrm{e}}$, transition multipolarities and total transition intensities, $I_{\text {total }}$, obtained for six low-energy transitions (four in $\mathrm{Au}$ and two in $\mathrm{Hg}$ ) are listed in table 3. The energies of the Auger electrons and conversion electron lines that have served the internal calibration are indicated by superscript ${ }^{(a)}$. The other electron energies have been obtained using the internal energy calibration procedure added to a shape analysis of the electron lines.

The $\mathrm{L}_{\mathrm{III}}$ electron line of the $17.17 \mathrm{keV}$ transition, M and $\mathrm{N}$ electron lines of the $9.0 \mathrm{keV}$ and $\mathrm{M}_{\mathrm{III}}$ and $\mathrm{O}$ electron lines of the $12.4 \mathrm{keV}$ transition are observed for the first time in this experiment.

In the ${ }^{185} \mathrm{Hg}$ nucleus, the $13 / 2^{+}$isomeric state decays partly to the $1 / 2^{-}$ground state at least by a cascade of three transitions. Two of them were unambiguously identified as an E3 65.3(1) keV and an $M 1+E 2$ 26.1(1) keV isomeric transitions [24]. A slightly smaller energy, 26.02(10) keV, has been found for the second transition in our analysis of the electron spectrum (table 3 ). 
Table 3. Low-energy conversion-electron data obtained from $\beta^{+} / \mathrm{EC}$ decay of ${ }^{185 \mathrm{~m}+\mathrm{g}} \mathrm{Hg}$ and isomeric transitions of ${ }^{185 \mathrm{~m}} \mathrm{Hg}$.

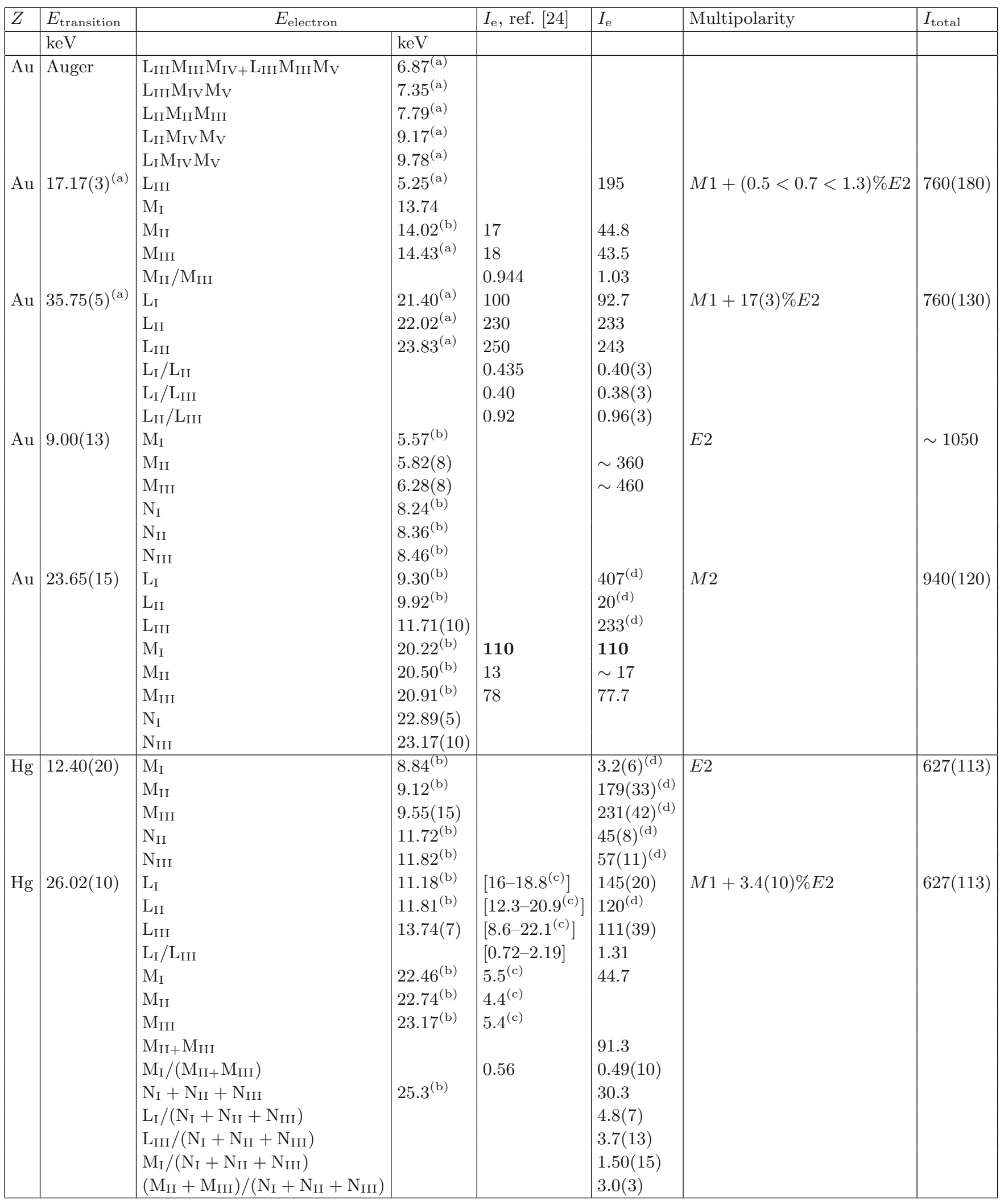

\footnotetext{
(a) Used for energy calibration.

(b) From transition and binding energies.

(c) Intensity per 100 decays of ${ }^{185 \mathrm{~m}} \mathrm{Hg}$.

(d) Intensity estimated from multipolarity, conversion coefficients and measured $I_{\mathrm{e}}$ or $I_{\text {total }}$ for the $E 212.4 \mathrm{keV}$ transition.
} 
Table 4. Data from ${ }^{185 \mathrm{~m}+\mathrm{g}} \mathrm{Hg} \alpha$-decay measurements, from [15,23,31-34]. The $q$ value reported in the last column corresponds to the nucleus-recoil energy, $E_{\mathrm{r}}$, added to the $\alpha$-particle kinetic energy, $E_{\alpha},\left(q=E_{\mathrm{r}}+E_{\alpha}\right)$. For $\alpha$ transition between ground states the $q$ value corresponds to the usual $Q_{\alpha}$ value.

\begin{tabular}{|c|c|c|c|c|c|c|c|c|c|}
\hline & $I^{\pi}$ & $\begin{array}{c}E_{\alpha}(\mathrm{keV}) \\
{[31]}\end{array}$ & $\begin{array}{c}E_{\alpha}(\mathrm{keV}) \\
{[15]}\end{array}$ & $\begin{array}{c}E_{\alpha}(\mathrm{keV}) \\
{[32]}\end{array}$ & $\begin{array}{c}\text { Coincident } \gamma \text {-rays } \\
{[15]}\end{array}$ & $\begin{array}{c}E_{\alpha}(\mathrm{keV}) \\
{[33,34]}\end{array}$ & $\begin{array}{c}I_{\alpha}(\%) \\
{[23,33,34]}\end{array}$ & $\begin{array}{l}\mathrm{HF} \\
{[33]}\end{array}$ & $q(\mathrm{keV})$ \\
\hline \multirow[t]{2}{*}{${ }^{185 \mathrm{~g}} \mathrm{Hg}$} & $1 / 2^{-}$ & $5652(15)$ & 5652 & 5652 & & $5653(5)$ & 5.8 & 1.15 & $5778(5)$ \\
\hline & & $5575(15)$ & 5560 & $\begin{array}{l}5575 \\
5560\end{array}$ & 79,94 & $5569(5)$ & 0.24 & 10.2 & $\begin{array}{l}5692(5) \\
5683\end{array}$ \\
\hline \multirow[t]{3}{*}{${ }^{185 \mathrm{~m}} \mathrm{Hg}$} & $13 / 2^{+}$ & & 5430 & & 161 & 5430 & $\leq 0.006$ & $\geq 45$ & 5550 \\
\hline & & & 5410 & & 161 & $5408(10)$ & 0.006 & 32 & $5528(10)$ \\
\hline & & $5375(15)$ & 5365 & & $61,106,118,161$ & $5372(8)$ & 0.024 & 6 & $5491(8)$ \\
\hline
\end{tabular}

The third isomeric transition must be then an $E 2$ transition with energy smaller than $16 \mathrm{keV}$ and the same total intensity as that of the $26.1 \mathrm{keV}$ isomeric transition [24]. A $9.55(15) \mathrm{keV}$ electron line is observed between the $\mathrm{L}_{\mathrm{I}}$ $\left(E_{\mathrm{e}}=9.30(15) \mathrm{keV}\right)$ electron line of the $23.65 \mathrm{keV}$ and the $9.78 \mathrm{keV}\left(\mathrm{L}_{\mathrm{I}} \mathrm{M}_{\mathrm{IV}} \mathrm{M}_{\mathrm{V}}\right)$ Auger line. If this line was an $\mathrm{L}_{\mathrm{III}}$ line corresponding to a $21.83 \mathrm{keV}$ transition, the $7.62 \mathrm{keV}$ $\mathrm{L}_{\mathrm{II}}$ line should be observed as a tail on the right of the $7.35 \mathrm{keV} \mathrm{L}_{\mathrm{III}} \mathrm{M}_{\mathrm{IV}} \mathrm{M}_{\mathrm{V}}$ Auger line, but it is not. Furthermore, the $18.55 \mathrm{keV} \mathrm{M}_{\mathrm{II}}$ and $18.98 \mathrm{keV} \mathrm{M}_{\mathrm{III}}$ lines of this $21.83 \mathrm{keV}$ that would have respectively $8.5 \%$ and $10 \%$ of the total intensity of the transition, should be also observed, with a larger intensity than that of the $\mathrm{M}_{\mathrm{I}}$ line of the 26.02 transition that has only $6.3 \%$ of the total intensity of the transition, but neither of these two electron lines is observed. Therefore, the $9.55 \mathrm{keV}$ electron line is an $\mathrm{M}_{\mathrm{III}}$ electron line, the $\mathrm{M}_{\mathrm{II}}, \mathrm{N}_{\mathrm{II}}$ and $\mathrm{N}_{\mathrm{III}}$ lines are then forming doublets with the $9.17 \mathrm{keV}\left(\mathrm{L}_{\mathrm{II}} \mathrm{M}_{\mathrm{IV}} \mathrm{M}_{\mathrm{V}}\right)$ Auger line, with the $\mathrm{L}_{\mathrm{III}}\left(E_{\mathrm{e}}=11.71(10) \mathrm{keV}\right)$ of the $23.65 \mathrm{keV}$ transition and with the $\mathrm{L}_{\mathrm{II}}\left(E_{\mathrm{e}}=11.81(10) \mathrm{keV}\right)$ of the $26.02 \mathrm{keV}$ transition, respectively. Unfortunately, given the complexity of the electron spectrum around $9.3 \mathrm{keV}$, the intensities of the $\mathrm{M}$ electron lines could not be determined and the intensities reported in column 6 of table 3 have been estimated from the total intensity of the $26.02 \mathrm{keV}$ transition using the E2 internal conversion coefficients. Thus, the careful analysis of the electron spectrum indicates that a $12.40(20) \mathrm{keV} E 2$ transition exists in the decay of the $13 / 2^{+}$isomeric state of ${ }^{185} \mathrm{Hg}$ that is then located at $E_{\mathrm{IS}}=103.72(40) \mathrm{keV}$.

We could imagine that the isomeric cascade consists of four transitions instead of three: two $M 1$ transitions instead of the $12.4 \mathrm{keV} E 2$ transition. The $9.55 \mathrm{keV}$ electron line could be then the $\mathrm{M}_{\mathrm{I}}$ lines of one $13.1 \mathrm{keV} M 1$ transition, the other one would have a smaller energy, which would locate the isomeric state at $E_{\mathrm{IS}}<117.5 \mathrm{keV}$. The existence of a fourth transition in the isomeric cascade cannot be completely excluded experimentally. However, this hypothesis is highly improbable since no $5 / 2^{-}$state is expected to be located at so low energy in ${ }^{185} \mathrm{Hg}$ from systematic energy studies performed for known states in

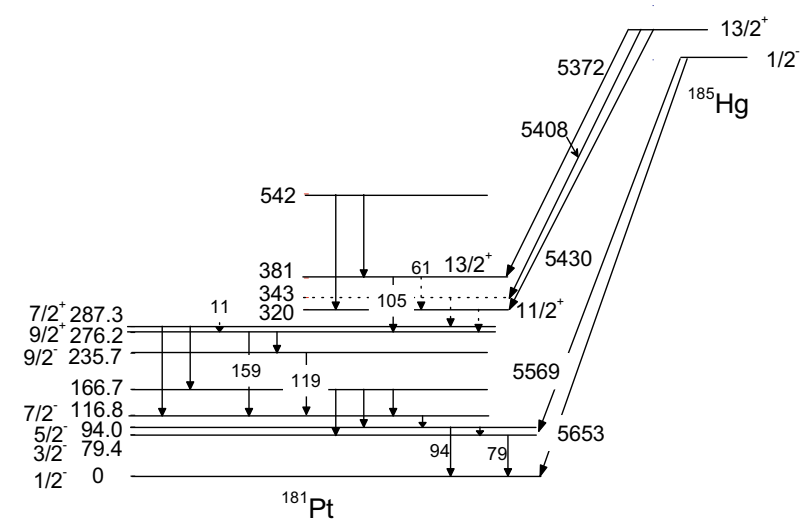

Fig. 4. Levels of the ${ }^{181} \mathrm{Pt}$ nucleus fed directly or indirectly from the ${ }^{185 \mathrm{~m}+\mathrm{g}} \mathrm{Hg} \alpha$ decay. The de-excitations of the $542 \mathrm{keV}$ level that allow the energy location of the $381 \mathrm{keV}$ level relatively to the $320 \mathrm{keV}$ level, are also shown. Information is taken from refs. [15-17,23,33,34], energies of the levels and transitions observed coincident with the $\alpha$ lines are given in $\mathrm{keV}$.

$Z=76,78$ and 80 and $N=105$ nucleus series (see fig. 10 in sect. 4).

It is worth noting that the conversion electron lines of the $51.9 \mathrm{keV}$ transition detected in the ${ }^{185} \mathrm{Tl} \beta^{+} / \mathrm{EC}$ decay (sect. 2) are not observed in the electron spectrum, which proves that this $51.9 \mathrm{keV}$ transition does not participate to the de-excitation of the $13 / 2^{+}$isomeric state to the $1 / 2^{-}$ ground state of ${ }^{185} \mathrm{Hg}$.

The $\alpha$ decay of ${ }^{185 \mathrm{~m}+\mathrm{g}} \mathrm{Hg}$ was studied extensively [15, $31,32]$ but at that time no information on the ${ }^{181} \mathrm{Pt}$ level scheme was available. Five $\alpha$ lines were observed: two from the $1 / 2^{-}$ground state and three from the $13 / 2^{+}$isomeric state of ${ }^{185} \mathrm{Hg}$. Some of these $\alpha$ lines were observed to be coincident with $\gamma$-rays [15]. The results from the $\alpha$ decay studies are summarized in table 4 . Since then, excited states of ${ }^{181} \mathrm{Pt}$ have been established from radioactivity [17] and (HI, $x \mathrm{n} \gamma$ ) reaction [16] studies. Almost all of the $\gamma$-rays observed in coincidence with the $\alpha$ particles are placed in the ${ }^{181} \mathrm{Pt}$ level scheme. The ${ }^{181} \mathrm{Pt}$ levels of interest for the subject are shown in fig. 4 . 
The 79.4 and $94.0 \mathrm{keV} \gamma$-rays are observed coincident with the $5569 \mathrm{keV} \alpha$ particles and the $79.4 \mathrm{keV} \gamma$ line appears clearly with a higher intensity than the $94.0 \mathrm{keV} \gamma$ line in the $\alpha-\gamma$ coincidence spectrum shown in ref. [15]. For the de-excitation of the $94.0 \mathrm{keV}$ state of ${ }^{181} \mathrm{Pt}$, the $\gamma$-ray intensity of the $79.4 \mathrm{keV}$ transition can be estimated to be $56(10) \%$ of that of the $94.0 \mathrm{keV}$ transition from the data reported in ref. [17], which means that the $5569 \mathrm{keV} \alpha$ line is a doublet. One of the $\alpha$ transitions feeds the $79.4 \mathrm{keV}$ state and the other one the $94.0 \mathrm{keV}$ state of the ${ }^{181} \mathrm{Pt}$ nucleus as previously suggested in ref. [32].

Two positive-parity states, $9 / 2^{+}$and $\left(7 / 2^{+}\right)$, have been located, respectively, at $276.2 \mathrm{keV}$ and $287.3 \mathrm{keV}$ in ${ }^{181} \mathrm{Pt}[17]$. The $11 / 2^{+}$and $13 / 2^{+}$states of the rotational band based on the $9 / 2^{+}$state have been established at 320 and $381 \mathrm{keV}$, respectively, and the $105 \mathrm{keV} 13 / 2^{+} \rightarrow 9 / 2^{+}$ transition has been observed [16]. This $105 \mathrm{keV}$ transition corresponds to the $106 \mathrm{keV} \gamma$-ray seen coincident with the $5372 \mathrm{keV} \alpha$ particles. The $13 / 2^{+}$state is located at $61 \mathrm{keV}$ above the $11 / 2^{+}$one, the $61 \mathrm{keV} \gamma$-ray observed coincident with the $5372 \mathrm{keV} \alpha$ line is then very likely the $13 / 2^{+} \rightarrow 11 / 2^{+} \gamma$ transition. This $61 \mathrm{keV} \gamma$-ray was too low in energy to be detected in the in-beam experiment. The 161 and $118 \mathrm{keV} \gamma$-rays also coincident with the $5372 \mathrm{keV} \alpha$ line are the 159.4 and $118.9 \mathrm{keV} \gamma$-rays that de-excite the $9 / 2^{+}$state at $276.2 \mathrm{keV}$ and the $9 / 2^{-}$ state at $235.7 \mathrm{keV}$ (see fig. 4). All of these data indicate very clearly that the $5372 \mathrm{keV} \alpha$ decay feeds the $13 / 2^{+}$ state located at $381 \mathrm{keV}$ in ${ }^{181} \mathrm{Pt}$. The $5430 \mathrm{keV} \alpha$ decay probably feeds the $11 / 2^{+}$state at $320 \mathrm{keV}$ since the energy difference of the q values corresponding to the 5430 and $5372 \mathrm{keV} \alpha$ particles is $59(10) \mathrm{keV}$ in perfect agreement with the $61 \mathrm{keV}$ energy difference between the $11 / 2^{+}$and $13 / 2^{+}$states (see fig. 4 and table 4 ).

The $5408 \mathrm{keV} \alpha$ decay feeds very likely an $11 / 2^{+}$or $13 / 2^{+}$state belonging to the rotational band, not observed up to now, based on the $7 / 2^{+}$state located at $287.3 \mathrm{keV}$ in the ${ }^{181} \mathrm{Pt}$ nucleus.

These $\alpha$-decay results of the ${ }^{185 \mathrm{~m}+\mathrm{g}} \mathrm{Hg}$ nucleus indicate that the isomeric state is located at $94(13) \mathrm{keV}$ above the ${ }^{185} \mathrm{Hg}$ ground state. This value is in agreement within the error bars with the electron determination $E_{\mathrm{IS}}=103.7(4) \mathrm{keV}$.

On the other hand, the energy of this isomeric state was determined to be $E_{\mathrm{IS}}=120(5) \mathrm{keV}$ from mass measurement performed by use of the Penning-trap mass spectrometer ISOLTRAP [35]. This value differs by $\Delta E_{\mathrm{IS}}=$ $16 \mathrm{keV}$, representing more than 3 standard deviations, from that determined from our conversion electron measurement. This $E_{\mathrm{IS}}$ value would imply an energy of $28.7(50) \mathrm{keV}$ for the $E 2$ transition of the cascade of which we should have observed the $\mathrm{L}_{\mathrm{II}}\left(E_{\mathrm{e}}=14.5(50) \mathrm{keV}\right)$, $\mathrm{L}_{\mathrm{III}}\left(E_{\mathrm{e}}=16.4(50) \mathrm{keV}\right), \mathrm{M}_{\mathrm{II}}\left(E_{\mathrm{e}}=25.4(50) \mathrm{keV}\right)$, and $\mathrm{M}_{\mathrm{III}}\left(E_{\mathrm{e}}=25.9(50) \mathrm{keV}\right)$ internal conversion electron lines since their intensities would be $35 \%, 39 \%, 9 \%$ and $10 \%$ of the total intensity of the transition respectively whereas, for the $26.02 \mathrm{keV}$ transition, the intensity of its $\mathrm{L}_{\mathrm{I}}$ electron line is $27 \%$ of its total intensity. In fig. 3, we can see that all electron lines observed with an energy higher than $9.8 \mathrm{keV}$ are properly identified, which means that the existence of an E2 28.7(50) keV transition with the same intensity as the $26.02 \mathrm{keV}$ has to be ruled out.

It is worth, however, noting that Schwarz et al. [35] mentioned the possible existence of an unexpected systematic error and added quadratically an error of $20 \mathrm{keV}$ before performing mass evaluation. If such a systematic error played a role on the determination of the isomeric state energy in ${ }^{185} \mathrm{Hg}$ then, the energy $E_{\mathrm{IS}}=120(21)$ deduced from mass measurement would be in reasonable agreement with both energies $E_{\mathrm{IS}}=94(13) \mathrm{keV}$ and $E_{\mathrm{IS}}=103.7(4) \mathrm{keV}$ obtained from the ${ }^{185 \mathrm{~m}+\mathrm{g}} \mathrm{Hg} \alpha$ decay and our electron measurement, respectively.

We shall adopt $E_{\mathrm{IS}}=103.7(4) \mathrm{keV}$ as energy of the isomeric state of the ${ }^{185} \mathrm{Hg}$ nucleus in the next sections.

\section{Study of the $\alpha$ decay of ${ }^{189 m+g} \mathrm{~Pb}$}

\subsection{Experimental procedure}

Lead radioactive atoms were produced in the same way as the thallium atoms (see sect. 2.1). The $\mathrm{Tl}$ atoms are surface ionized in the hot cavity whereas the $\mathrm{Pb}$ atoms are selectively photo-ionized in a three-step resonant process using the Resonance Ionization Laser Ion Source, RILIS [36,37], of the ISOLDE facility. To ionize the lead atoms the laser beam wave length was: for the first excitation step, $\lambda=283.3 \mathrm{~nm}$, for the second excitation step, $\lambda=600.2 \mathrm{~nm}$ and for the ionization step, $\lambda=511$ and $578 \mathrm{~nm}[11,12]$. The lead ions extracted by a $60 \mathrm{kV}$ high voltage were mass-separated and then guided to a counting station. The ion beam was collected into the tape of a tape transport system with precise and reliable movements [38]. Then the source was moved in front of three detectors: one implanted Si $\alpha$ detector $\left(100 \mathrm{~mm}^{2}\right.$ area and $100 \mu \mathrm{m}$ thickness) with $14 \mathrm{keV}$ FWHM resolution at $5.7 \mathrm{MeV}$ and two coaxial $\mathrm{Ge}(\mathrm{HP}) \gamma$ detectors $(60 \%$ relative efficiency, $3.6 \mathrm{keV}$ FWHM resolution at $1.33 \mathrm{MeV}$ and $70 \%$ relative efficiency, $4.3 \mathrm{keV}$ FWHM resolution at $1.33 \mathrm{MeV})$.

Two measurements have been realized. For the first one the laser beam frequency of the first excitation step was set at $17643.20 \mathrm{~cm}^{-1}$ (before frequency doubling) to ionize with a good efficiency both the atoms with ${ }^{189 \mathrm{~m}} \mathrm{~Pb}$ and ${ }^{189 \mathrm{~g}} \mathrm{~Pb}$ nuclei. The ion beam was collected for $t_{\mathrm{c}}=$ $300 \mathrm{~ms}$ immediately after the proton pulse and measured for $t_{\mathrm{m}}=52 \mathrm{~s}$ after the source transport time, $t_{\mathrm{t}}=315 \mathrm{~ms}$. Both $\alpha-\gamma$ and $\gamma-\gamma$ coincidence measurements were performed for 10 hours. For the second one the laser beam was used in a narrow band mode and a frequency scan of 28 steps of $\delta \nu=0.02 \mathrm{~cm}^{-1}$ has been realized to obtain hyperfine spectra by measuring the $\alpha$-line and $\gamma$-line intensity changes against the frequency value. For every frequency step one source was collected for $t_{\mathrm{c}}=2.5 \mathrm{~s}$ immediately after the proton pulse and measured for $t_{\mathrm{m}}=54 \mathrm{~s}$ after the tape movement. This measurement has been repeated four times: two while the laser frequency was increased and two while it was decreased. 


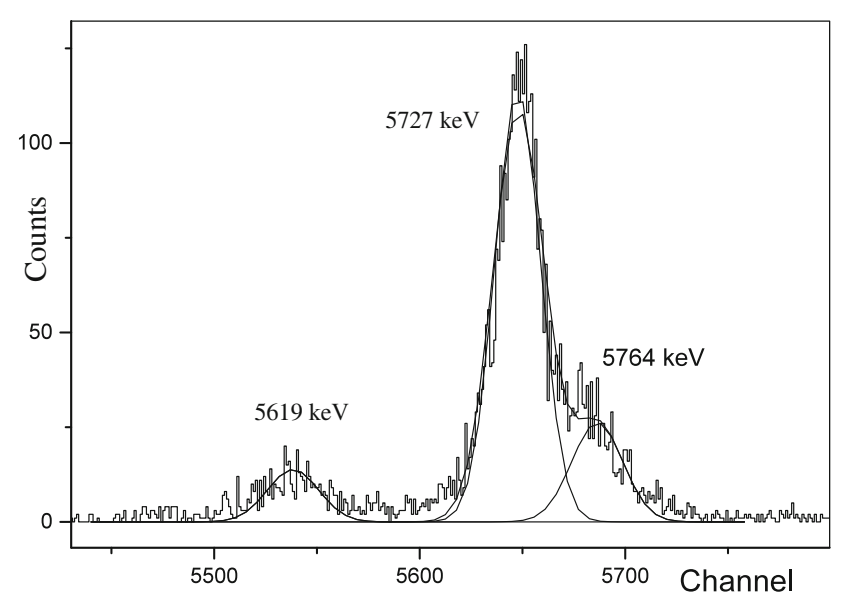

Fig. 5. $\alpha-\gamma$ matrix projection on the $\alpha$ axis, energies are given in $\mathrm{keV}$.

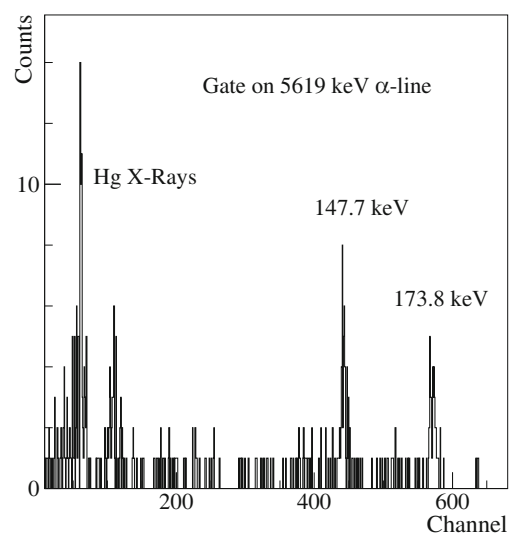

Fig. 6. $\gamma$ spectrum for gate on the $5619 \mathrm{keV} \alpha$ line, energies are given in $\mathrm{keV}$.

The data are treated using the COMET-NARVAL acquisition system (see sect. 2.1).

The experimental procedure has been described with many more details in refs. [12,39].

\subsection{Results}

The $\alpha$ - $\gamma$ matrix projection on the $\alpha$ axis and the $\gamma$ spectrum observed in coincidence with the $5619 \mathrm{keV} \alpha$ particles are shown in figs. 5 and 6 . Three $\alpha$ decays of the ${ }^{189} \mathrm{~Pb}$ nucleus were observed with energies of 5619 , 5727 and $5764 \mathrm{keV}$. Only a $5730 \mathrm{keV} \alpha$ decay was already known [40]. The 5619 and $5764 \mathrm{keV} \alpha$ decays were therefore observed for the first time. We have to note that in fig. 5 the $5619 \mathrm{keV} \alpha$ line seen in the spectrum is mainly due to $\alpha-\gamma$ true coincidences and represents around $4 \%$ of the detected $5619 \mathrm{keV} \alpha$ particles whereas the $5727 \mathrm{keV}$ and $5764 \mathrm{keV} \alpha$ lines are only due to $\alpha-\gamma$ random coincidences and represent only around $0.7 \%$ of the detected $\alpha$ particles. The 147.7 and $173.8 \mathrm{keV} \gamma$-rays appear to be coincident with the $5619 \mathrm{keV} \alpha$ particles. No $\gamma$-ray has been seen coincident with the 5727 and $5764 \mathrm{keV} \alpha$ particles. These two $\gamma$-rays were also observed in our ${ }^{185} \mathrm{Tl}$

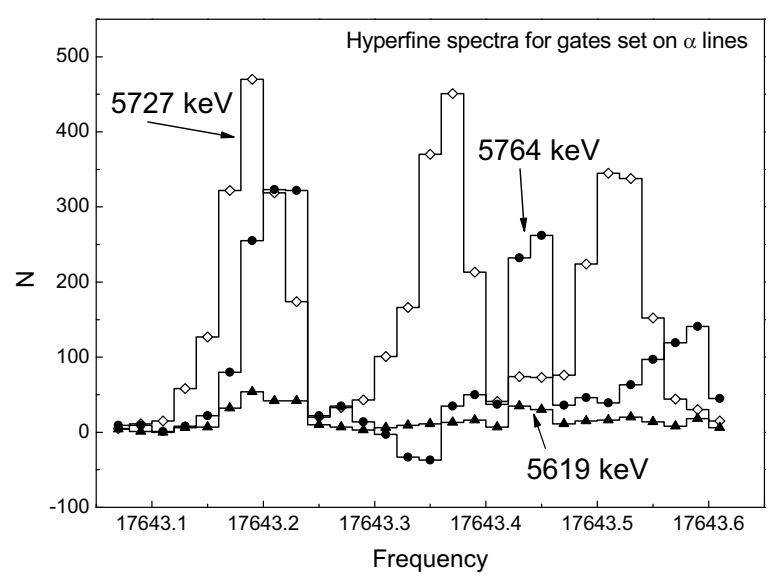

Fig. 7. Hyperfine spectra for gates set on the 5727, 5764 and $5619 \mathrm{keV} \alpha$ lines, $N$ is the $\alpha$-line intensity. Frequency values in $\mathrm{cm}^{-1}$ correspond to the laser beam of the first excitation step before doubling.

$\beta^{+} / \mathrm{EC}$ decay study and they de-excite the $173.9 \mathrm{keV}$ level of ${ }^{185} \mathrm{Hg}$ (see sect. 2.2 and part A of fig. 2). Thus the $\alpha-\gamma$ coincidence results indicate clearly that the $5619 \mathrm{keV} \alpha$ decay feeds directly the $173.9 \mathrm{keV}$ level of ${ }^{185} \mathrm{Hg}$. The energy difference of the $q$ values corresponding to the 5764 and $5619 \mathrm{keV} \alpha$ decays, $\Delta q=149(4) \mathrm{keV}$, is consistent with the $5764 \mathrm{keV} \alpha$ decay feeding the $26.0 \mathrm{keV}$ level of ${ }^{185} \mathrm{Hg}$.

The hyperfine spectra corresponding to the $13 / 2$ and $3 / 2$ states of the neutron-deficient $\mathrm{Pb}$ nuclei are very different and well identified $[12,39]$. The intensity variations of the $\alpha$ lines with the laser beam frequency have provided the hyperfine spectra shown in fig. 7 . The hyperfine spectrum obtained for a gate set on the $5727 \mathrm{keV} \alpha$ line indicates unambiguously that these $\alpha$ particles come from the $13 / 2$ state of ${ }^{189} \mathrm{~Pb}$ whereas the hyperfine spectra obtained for the two other $\alpha$ lines indicate that both the 5764 and $5619 \mathrm{keV} \alpha$ particles are emitted by the $3 / 2$ state of ${ }^{189} \mathrm{~Pb}$.

The $\alpha$ results are given in table 5 and the $\alpha$-decay scheme of ${ }^{189 \mathrm{~m}+\mathrm{g}} \mathrm{Pb}$ is shown in fig. 8 .

These results allow us to locate the $13 / 2^{+}$at $40(4) \mathrm{keV}$ above the $3 / 2^{-}$ground state of the ${ }^{189} \mathrm{~Pb}$ nucleus. The intensity of the direct $\beta^{+} / \mathrm{EC}$ decay of the $3 / 2^{-}{ }^{189} \mathrm{~Pb}$ ground state towards the $1 / 2^{+}{ }^{189} \mathrm{Tl}$ ground state being unknown, only limits could be estimated for the absolute intensities, $I$, and hindrance factors (determined as described in ref. [42]), HF, of the $\alpha$ decays of the $3 / 2^{-}$ ground state of ${ }^{189} \mathrm{~Pb}$ (see table 5). It is worth noting that the systematic error mainly due to calibration uncertainty, changes in the same way the $E_{\alpha}$ values since they differ of only some percents, which results to an error of some percents of the systematic error on the $\Delta q$ difference (i.e. around $0.1 \mathrm{keV}$ for ${ }^{185} \mathrm{Hg}$ ). The systematic error plays a role on the mass determination accuracy, $Q_{\alpha}$ value, only.

It is clear that the determination of the energy location of an isomeric state can serve to estimate the energy location of the isomeric state of its parent provided the energies of the $\alpha$ particles emitted by the two parent iso- 
Table 5. $\alpha$-particle data for $\alpha$ decay of the ${ }^{189 \mathrm{~m}+\mathrm{g}} \mathrm{Pb}$ isomers. Values in first and second parentheses are statistical and systematic errors on the $\alpha$ energies, respectively. HF: Hindrance factors are determined using the way described in ref. [42], $q=E_{\mathrm{r}}+E_{\alpha}$, the $q$ value corresponds to the usual $Q_{\alpha}$ value for the $\alpha$ transition between the ground states.

\begin{tabular}{|c|c|c|c|c|c|c|c|c|c|}
\hline & $I^{\pi}$ & $\begin{array}{c}T_{1 / 2}(\mathrm{~s}) \\
{[39]}\end{array}$ & $\begin{array}{c}E_{\alpha}(\mathrm{keV}) \\
{[40]}\end{array}$ & $E_{\alpha}(\mathrm{keV})$ & Coincident $\gamma$-rays & $I_{\alpha}$ & $I_{\alpha}(\%)$ & $\mathrm{HF}$ & $q(\mathrm{keV})$ \\
\hline${ }^{189} \mathrm{~Pb}$ & $3 / 2^{-}$ & $39(8)$ & & $\begin{array}{l}5764(3)(5) \\
5619(2)(5)\end{array}$ & $147.7,173.8$ & $\begin{array}{l}23 \\
2.5\end{array}$ & $\begin{array}{l}\leq 0.36 \\
\leq 0.04\end{array}$ & $\begin{array}{l}\geq 4 \\
\geq 8\end{array}$ & $\begin{array}{l}5889 \\
5740\end{array}$ \\
\hline & $13 / 2^{+}$ & $50(3)$ & $5730(10)$ & $5727(2)(5)$ & & 100 & $\approx 0.4^{(\mathrm{a})}$ & $\approx 3.4$ & 5851 \\
\hline
\end{tabular}

(a) From [41].

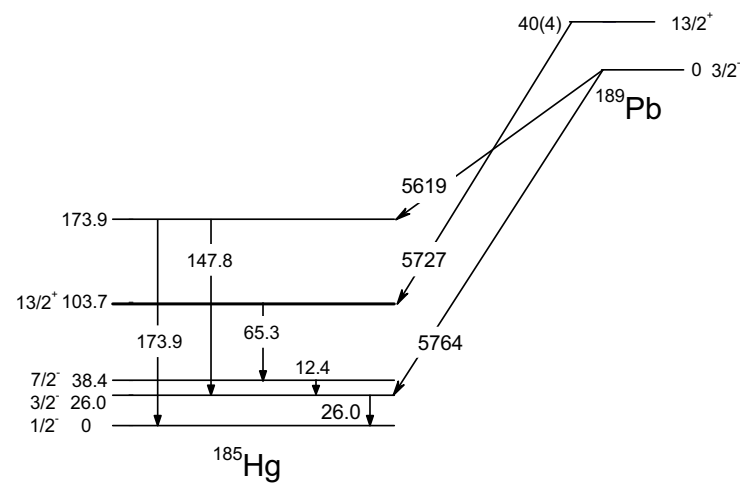

Fig. 8. $\alpha$-decay schemes of the ${ }^{189 \mathrm{~m}+\mathrm{g}} \mathrm{Pb}$ isomers. Energies are given in $\mathrm{keV}$.

mers are known and located in a $\alpha$-decay scheme. The $\alpha$-decay data (spin and parity values of the initial and final states, $I_{\mathrm{i}}^{\pi}, I_{\mathrm{f}}^{\pi}$, half-life of the initial state, $T_{1 / 2}$, energy of the $\alpha$ particles, $E_{\alpha}, \alpha$-transition intensity, $I_{\alpha}, q$ value $\left(E_{\mathrm{r}}+E_{\alpha}\right)$, hindrance factor, $\left.\mathrm{HF}\right)$ known for the $\alpha$-emitter chains starting with the ${ }^{195 m+g} \mathrm{Rn},{ }^{197 m+g} \mathrm{Rn},{ }^{199 m+g} \mathrm{Rn}$ nuclei have been listed in table 6 . The partial $\alpha$-decay schemes of the nuclei of these three $\alpha$-emitter chains are shown in fig. 9. Only the main $\alpha$ decays are represented. The energies of the $\alpha$ particles from ${ }^{193 \mathrm{~m}+\mathrm{g}} \mathrm{Po}$ (table 6 ) added to the energy location at $40(4) \mathrm{keV}$ of the $13 / 2^{+}$isomeric state of ${ }^{189} \mathrm{~Pb}$ determined in the present work have allowed us to locate the $13 / 2^{+}$isomeric state at $95(7) \mathrm{keV}$ above the $3 / 2^{-}$ground state of the ${ }^{193} \mathrm{Po}$ nucleus. In the same way, $13 / 2^{+}$isomeric states have been located at $194(12) \mathrm{keV}$ and $63(29) \mathrm{keV}$ above the $3 / 2^{-}$ground states of the ${ }^{197} \mathrm{Rn}$ and ${ }^{187} \mathrm{Hg}$ nuclei, respectively. From mass measurement performed using the ISOLTRAP setup the isomeric state of ${ }^{187} \mathrm{Hg}$ has been located at 54(7) keV [35]. This more precise value is in agreement within the error bars with our value and will be adopted later on (see fig. 9). No $\alpha$ particle from the $13 / 2^{+}$isomeric state of ${ }^{191} \mathrm{~Pb}$ has been observed up to now, which prevents us from estimating the energy location of the $13 / 2^{+}$isomeric states of the ${ }^{191} \mathrm{~Pb},{ }^{195} \mathrm{Po}$ and ${ }^{199} \mathrm{Rn}$ nuclei (noted as $y$, $y+95$ and $y+168$, respectively, in fig. 9).
As for the third chain, several experiments have shown that there is no $13 / 2^{+}$isomeric state with half-life in the order of $1 \mathrm{~s}$ in the ${ }^{183} \mathrm{Hg}$ nucleus: i) all the observed $\alpha$ decays emitted by this nucleus come from the $1 / 2^{-}$ ground state, ii) no internal-conversion electron line due to isomeric transitions in ${ }^{183} \mathrm{Hg}$ has been observed [65], iii) whereas the $\beta^{+} / \mathrm{EC}$ decay of the $13 / 2^{+}$isomeric state of ${ }^{185} \mathrm{Hg}$ feeds states with I value up to $17 / 2$ in ${ }^{185} \mathrm{Au}[24$, $66]$, the $\beta^{+} / \mathrm{EC}$ decay of ${ }^{183} \mathrm{Hg}$ feeds only states with $I<13 / 2$ in ${ }^{183} \mathrm{Au}$ since no $\gamma$-ray observed in the inbeam study has been seen in the $\beta^{+} /$EC decay study [65, $67]$. Thus, the $13 / 2^{+}$observed as a isomeric state in the in-beam study of ${ }^{183} \mathrm{Hg}[68,69]$ is very likely located at a higher energy than either a $9 / 2^{-}$or a $9 / 2^{+}$ state.

The $9 / 2$ states expected to be located at low energy in ${ }^{183} \mathrm{Hg}$ can be deduced from the energy evolution of the level unambiguously identified in the isotones $N=103$ and $N=105$, see fig. 10 . In the rotational bands built on the $1 / 2^{-}$ground states of the ${ }^{179,181,183} \mathrm{Pt}$ and ${ }^{183} \mathrm{Hg}$ nuclei the $3 / 2^{-}$states are located at less than $20 \mathrm{keV}$ under the $5 / 2^{-}$states. This property indicates unambiguously that the $1 / 2^{-}$ground states are the $1 / 2^{-}[521]$ Nilsson states corresponding to a prolate nuclear shape $[69$, 70]. Shi et al. [69] and Lane et al. [68] have observed the $1 / 2^{-}[521]$ rotational band in ${ }^{183} \mathrm{Hg}$ from in-beam experiments. Their results differ only for the two first $3 / 2^{-} \rightarrow 1 / 2^{-}$and $5 / 2^{-} \rightarrow 1 / 2^{-}$transitions. Shi et al. [69] observed an $88.9 \mathrm{keV} \gamma$-ray coincident with the $\gamma$ lines of the favoured $1 / 2^{-}[521]$ band and an $86.5 \mathrm{keV} \gamma$-ray coincident with the $\gamma$ lines of the disfavoured $1 / 2^{-}[521]$ band. Therefore, they have attributed the $88.9 \mathrm{keV}$ and $86.5 \mathrm{keV}$ $\gamma$-rays to the $5 / 2^{-} \rightarrow 1 / 2^{-}$and $3 / 2^{-} \rightarrow 1 / 2^{-}$transitions, respectively. Lane et al. [68] saw a $66.8 \mathrm{keV}$ and an $87 \mathrm{keV} \gamma$-rays coincident with a $\gamma$ line of the favoured $1 / 2^{-}[521]$ band and determined an $M 1+E 2$ multipolarity for the $66.8 \mathrm{keV}$ transition. Therefore, they have tentatively attributed the $66.8 \mathrm{keV}$ and $87 \mathrm{keV} \gamma$-rays to the $3 / 2^{-} \rightarrow 1 / 2^{-}$and $5 / 2^{-} \rightarrow 1 / 2^{-}$transitions, respectively. Thus, the $9 / 21 / 2^{-}[521]$ has been located at $288 \mathrm{keV}$ [69] and at $286 \mathrm{keV}$ [68] in ${ }^{183} \mathrm{Hg}$, in fig. 10 we have adopted the data from [69] for the $1 / 2^{-}$[521] band since three interband transitions supported their results. 
Table 6. $\alpha$-decay data: spin and parity values of the initial and final states, $I_{\mathrm{i}}^{\pi}, I_{\mathrm{f}}^{\pi}$, half-life of the initial state, $T_{1 / 2}$, energy of the $\alpha$ particles, $E_{\alpha}, \alpha$-transition intensity, $I_{\alpha}, q\left(E_{\mathrm{r}}+E_{\alpha}\right)$ value and Hindrance factor, HF, known for the $\alpha$-emitter chains starting with the ${ }^{195 \mathrm{~m}+\mathrm{g}} \mathrm{Rn},{ }^{197 \mathrm{~m}+\mathrm{g}} \mathrm{Rn},{ }^{199 \mathrm{~m}+\mathrm{g}} \mathrm{Rn}$ nuclei. For $\alpha$ transition between ground states the $q$ value corresponds to the usual $Q_{\alpha}$ value.

\begin{tabular}{|c|c|c|c|c|c|c|c|c|c|c|}
\hline & $\mathrm{A}$ & $I_{\mathrm{i}}^{\pi}$ & $I_{\mathrm{f}}^{\pi}$ & $T_{1 / 2}(\mathrm{~s})$ & $E_{\alpha}(\mathrm{keV})$ & $I_{\alpha}(\%)$ & $q(\mathrm{keV})$ & $\mathrm{HF}$ & & Other references \\
\hline $\mathrm{Rn}$ & 199 & $\left(3 / 2^{-}\right)$ & $\left(3 / 2^{-}\right)$ & $0.59(3)$ & $6989(6)$ & 94 & 7132 & 0.98 & {$[43]$} & {$[44-47]$} \\
\hline & 199 & $\left(13 / 2^{+}\right)$ & $\left(13 / 2^{+}\right)$ & $0.31(2)$ & $7060(6)$ & 97 & 7205 & 0.9 & & \\
\hline & 197 & $\left(3 / 2^{-}\right)$ & $\left(3 / 2^{-}\right)$ & $0.066(16)$ & $7260(7)$ & 100 & 7410 & 1.5 & {$[48]$} & {$[49]$} \\
\hline & 197 & $\left(13 / 2^{+}\right)$ & $\left(13 / 2^{+}\right)$ & $0.021(5)$ & $7357(6)$ & 100 & 7509 & 1.0 & & \\
\hline & 195 & $\left(3 / 2^{-}\right)$ & $\left(3 / 2^{-}\right)$ & $0.006(3)$ & $7536(11)$ & 99.75 & 7694 & 2.4 & {$[50]$} & {$[51]$} \\
\hline & 195 & $\left(13 / 2^{+}\right)$ & $\left(13 / 2^{+}\right)$ & $0.005(3)$ & $7555(11)$ & 99.8 & 7713 & 2.3 & & \\
\hline Po & 195 & $\left(3 / 2^{-}\right)$ & $3 / 2^{-}$ & $4.64(9)$ & $6606(5)$ & 99.56 & 6744 & 1.6 & {$[52]$} & {$[47,50,53]$} \\
\hline & 195 & & $\left(5 / 2^{-}\right)$ & & $6399(10)$ & 0.054 & 6533 & 465 & & \\
\hline & 195 & & $\left(3 / 2^{-}\right)$ & & $6027(5)$ & 0.34 & 6153 & 2.0 & & \\
\hline & 195 & & & & $5985(10)$ & 0.036 & 6110 & 12 & & \\
\hline & 195 & $\left(13 / 2^{+}\right)$ & $13 / 2^{+}$ & $1.92(2)$ & $6699(5)$ & 99.83 & 6839 & 1.6 & & \\
\hline & 195 & & $13 / 2^{+}$ & & $6047(5)$ & 0.17 & 6174 & 2.1 & & \\
\hline & 193 & $\left(3 / 2^{-}\right)$ & $3 / 2^{-}$ & $0.42(4)$ & $6948(4)$ & 99.3 & 7095 & 2.5 & {$[54]$} & {$[47,49,53,55,56]$} \\
\hline & 193 & & $3 / 2^{-}$ & & $6420(20)$ & 0.7 & 6556 & 3.7 & & \\
\hline & 193 & $\left(13 / 2^{+}\right)$ & $13 / 2^{+}$ & $0.24(1)$ & $7002(4)$ & 99 & 7150 & 2.1 & & \\
\hline & 193 & & $13 / 2^{+}$ & & $6375(15)$ & 0.8 & 6510 & 1.2 & & \\
\hline & 191 & $\left(3 / 2^{-}\right)$ & $13 / 2^{+}$ & $0.022(1)$ & $7336(15)$ & 14.9 & 7493 & 21 & {$[57]$} & {$[58-60]$} \\
\hline & 191 & & $3 / 2^{-}$ & & $7334(5)$ & 76 & 7491 & 4 & & \\
\hline & 191 & & $\left(3 / 2^{-}\right)$ & & $6966(10)$ & 7.9 & 7115 & 2.3 & & \\
\hline & 191 & $\left(13 / 2^{+}\right)$ & $13 / 2^{+}$ & $0.093(3)$ & $7376(5)$ & 45.7 & 7534 & 70 & & \\
\hline & 191 & & & & $6909(15)$ & 3.7 & 7057 & 26 & & \\
\hline & 191 & & $\left(13 / 2^{+}\right)$ & & $6888(5)$ & 36 & 7035 & 2.2 & & \\
\hline & 191 & & & & $6815(15)$ & 9.6 & 6961 & 4.5 & & \\
\hline & 191 & & & & $6790(15)$ & 0.5 & 6935 & 76 & & \\
\hline $\mathrm{Pb}$ & 191 & $3 / 2^{-}$ & $3 / 2^{-}$ & $79.8(5)$ & $5310(10)$ & 0.013 & 5424 & 0.46 & {$[52]$} & {$[41,57,61]$} \\
\hline & 189 & $3 / 2^{-}$ & $3 / 2^{-}$ & $39(8)$ & $5764(3)(5)$ & $\leq 0.36$ & 5889 & $\geq 4$ & & \\
\hline & 189 & & & & $5619(2)(5)$ & $\leq 0.04$ & 5740 & $\geq 8$ & & - \\
\hline & 189 & $13 / 2^{+}$ & $13 / 2^{+}$ & $51(3)$ & $5727(2)(5)$ & $0.4^{(\mathrm{a})}$ & 5851 & 3.4 & & \\
\hline & 187 & $3 / 2^{-}$ & $(1 / 2,3 / 2,5 / 2)^{-}$ & $15.2(3)$ & $6194(10)$ & 4.2 & 6329 & 9.1 & {$[62]$} & {$[61,63]$} \\
\hline & 187 & & $\left(3 / 2^{-}\right)$ & & $5993(10)$ & 2.8 & 6124 & 2.2 & & \\
\hline & 187 & $13 / 2^{+}$ & $13 / 2+$ & $18.3(3)$ & $6077(7)$ & 12 & 6210 & 1.4 & & \\
\hline $\mathrm{Hg}$ & 187 & $3 / 2^{-}$ & $3 / 21 / 2^{-}[521]$ & $114(18)$ & $5035(20)$ & $>2.5 E-04$ & 5145 & $<50$ & {$[23]$} & {$[31]$} \\
\hline & 187 & $13 / 2^{+}$ & $13 / 29 / 2^{+}[624]$ & 144(18) & $4870(20)$ & $>1.2 E-04$ & 4976 & $<14$ & & \\
\hline & 185 & $1 / 21 / 2^{-}[521]$ & $1 / 21 / 2^{-}[521]$ & $49.1(10)$ & $5653(5)$ & 5.8 & 5778 & 1.15 & {$[33]$} & {$[15,23,31,32]$} \\
\hline & 185 & & $3 / 2$ et $5 / 21 / 2^{-}[521]$ & & $5569(5)$ & 0.24 & 5692 & 10.2 & & \\
\hline & 185 & $13 / 2^{+}$ & $11 / 29 / 2^{+}[624]$ & & 5430 & $\leq 0.006$ & 5550 & $\geq 45$ & & \\
\hline & 185 & & $(11 / 2,13 / 2) 7 / 2^{+}[633]$ & $21.6(15)$ & $5408(10)$ & 0.006 & 5528 & 32 & & \\
\hline & 185 & & $13 / 29 / 2^{+}[624]$ & & $5372(8)$ & 0.024 & 5491 & 6 & & \\
\hline & 183 & $1 / 21 / 2^{-}[521]$ & $1 / 21 / 2^{-}[521]$ & $9.4(7)$ & $5904(5)$ & 11 & 6036 & 1.8 & {$[64]$} & {$[32]$} \\
\hline & 183 & & $3 / 21 / 2^{-}[521]$ & & $5834(10)$ & 0.61 & 5964 & 15 & & \\
\hline & 183 & & $5 / 21 / 2^{-}[521]$ & & $5819(10)$ & 0.43 & 5949 & 18 & & \\
\hline & 183 & & $7 / 21 / 2^{-}[521]$ & & $5669(10)$ & 0.035 & 5796 & 48 & & \\
\hline
\end{tabular}

\footnotetext{
(a) From ref. [41].
} 


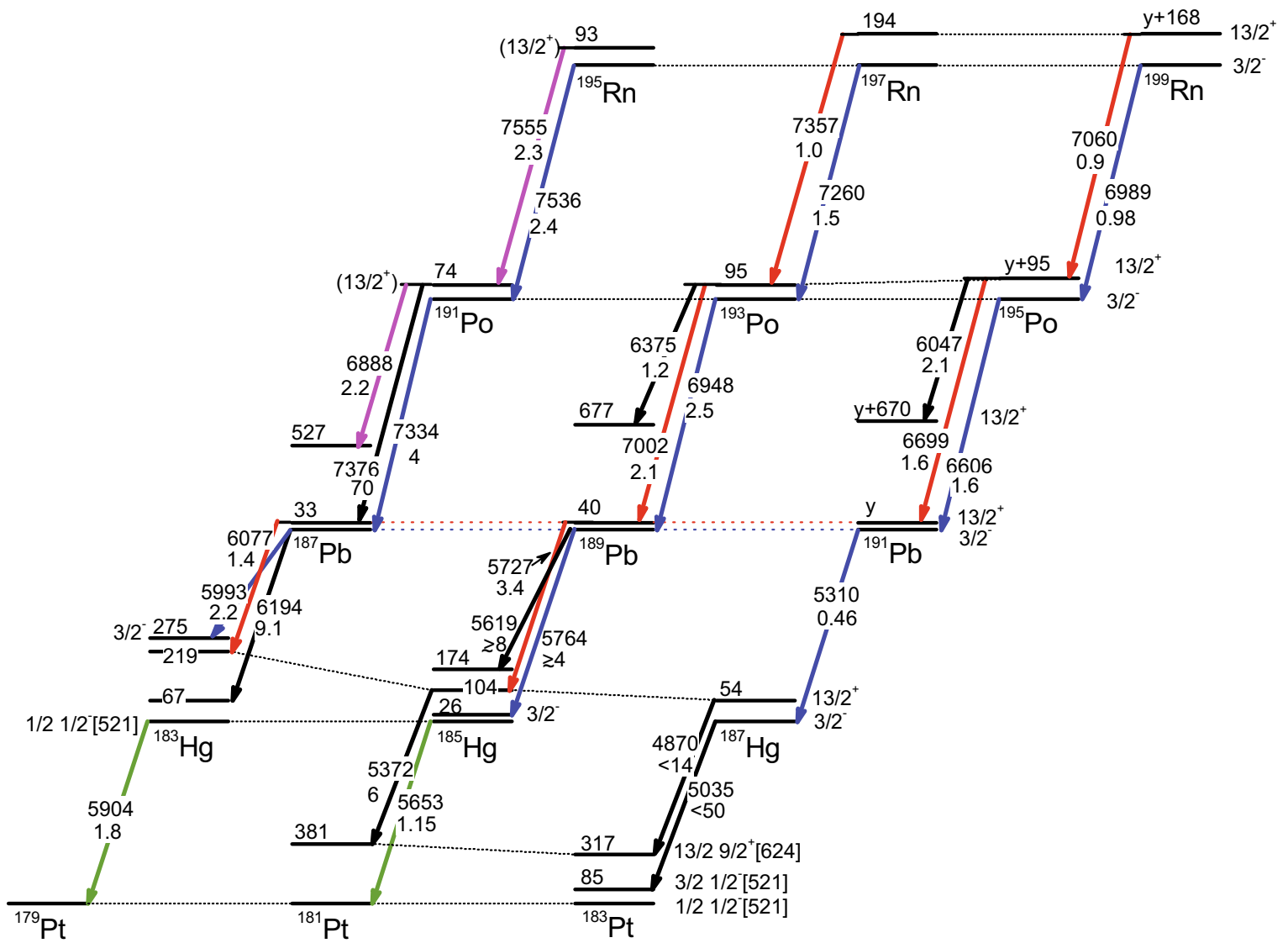

Fig. 9. Partial decay schemes of the nuclei of the $\alpha$-emitter chains starting with the ${ }^{195 \mathrm{~m}+\mathrm{g}} \mathrm{Rn},{ }^{197 \mathrm{~m}+\mathrm{g}} \mathrm{Rn},{ }^{199 \mathrm{~m}+\mathrm{g}} \mathrm{Rn}$ nuclei. Energies are given in $\mathrm{keV}$ and $\mathrm{HF}$ values are indicated below the $\alpha$ energies.

A $9 / 2^{+}[624]$ state due to the strong coupling of the $i_{13 / 2}$ neutron with the core is also expected lying at low energy in ${ }^{183,185} \mathrm{Hg}$. However, this $9 / 2^{+}$state is probably located slightly above the $13 / 2^{+}$level from the results obtained on ${ }^{183,185} \mathrm{Hg}$ using in-beam experiments [68,69,71]. The properties of the rotational bands built on the $7 / 2^{-}$levels lying at low energy in ${ }^{179,181}$ Os $[72-74],{ }^{181,183} \mathrm{Pt}[16$, $17,75,76]$ and ${ }^{183,185} \mathrm{Hg}$ nuclei $([14,24,68,69,71]$ and this work) indicate very clearly that these $7 / 2^{-}$levels are the $7 / 2^{-}[514]$ Nilsson states. In ${ }^{183} \mathrm{Hg}$ the $7 / 2^{-}[514]$ state has not been placed in the level scheme but from fig. 10 we can estimate that it should be located at $120(10) \mathrm{keV}$. The $9 / 2 \rightarrow 7 / 2$ intra-band transition energy is $105 \mathrm{keV}$, which gives an energy location of the $9 / 27 / 2^{-}[514]$ state around $225 \mathrm{keV}$. This latter state that is then the $9 / 2$ level located at the lowest energy is indeed the best candidate to serve to de-excite the $13 / 2^{+}$isomeric state. Thus, in ${ }^{183} \mathrm{Hg}$ the $13 / 2^{+}$state is expected to be located at a higher energy than $225 \mathrm{keV}$.

This $13 / 2^{+}$isomeric state in ${ }^{183} \mathrm{Hg}$ is very probably fed directly by the unhindered $(\mathrm{HF}=1.4) 6077 \mathrm{keV} \alpha$ transition coming from the $13 / 2^{+}$state of ${ }^{187} \mathrm{~Pb}$. From a $\alpha$-decay study of ${ }^{191} \mathrm{Po}$ Andreyev et al. [60] have located the $3 / 2^{-}$state in ${ }^{187} \mathrm{~Pb}$ at $E_{\mathrm{IS}}=2(15) \mathrm{keV}$ above the $13 / 2^{+}$state that is then the probable ground state of ${ }^{187} \mathrm{~Pb}$. From this $E_{\mathrm{IS}}=2(15) \mathrm{keV}$ value in ${ }^{187} \mathrm{~Pb}$ we can

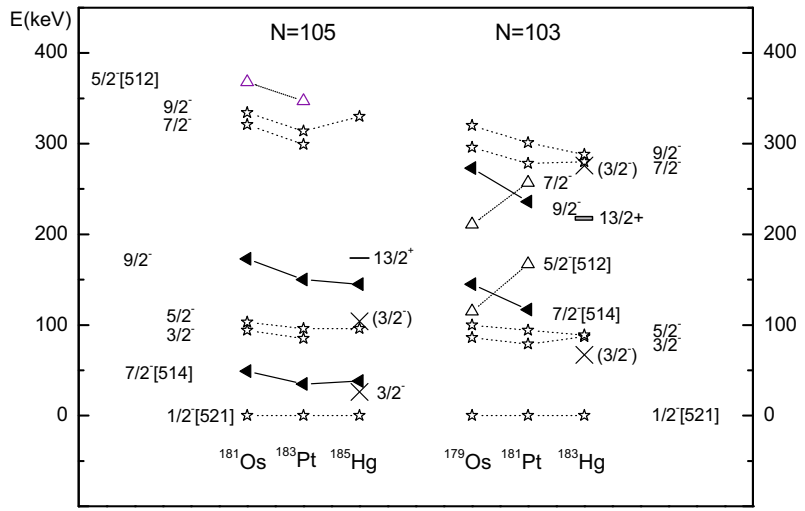

Fig. 10. Systematics of the state energies known in the $N=$ 105 and $N=103$ isotones: stars for the $1 / 2^{-}$[521] band states, open triangles for the $5 / 2^{-}$[512] band states, full triangles for the $7 / 2^{-}[514]$ band states and $\times$ for $3 / 2^{-}$and $\left(3 / 2^{-}\right)$states. $13 / 2^{+}$isomeric state is shown as a horizontal line in ${ }^{185} \mathrm{Hg}$ and as a rectangle (because of the large uncertainty $E_{\mathrm{IS}}=$ $219(18) \mathrm{keV})$ in ${ }^{183} \mathrm{Hg}$.

deduce an energy location of the $13 / 2^{+}$state in ${ }^{183} \mathrm{Hg}$ at $E_{\mathrm{IS}}=184(19) \mathrm{keV}$.

Besides, mass measurements performed using ISOLTRAP have allowed Weber et al. [77] to locate 
Table 7. Known $\beta, I$ and $\mu$ values of the isomeric and ground states of the $\mathrm{Pb}, \mathrm{Hg}$ and $\mathrm{Pt}$ nuclei next to the ${ }^{185} \mathrm{Hg}$ and ${ }^{189} \mathrm{~Pb}$ nuclei and of the $3 / 21 / 2^{-}[510]$ state of ${ }^{183} \mathrm{Os}$.

\begin{tabular}{|l|l|l|l|l|l|l|l|l|}
\hline & $\mathrm{A}$ & $I_{\mathrm{gs}}$ & $\mu\left(\mu_{\mathrm{N}}\right)$ & $\left\langle\beta^{2}\right\rangle^{1 / 2}$ & $I_{\mathrm{is}}$ & $\mu\left(\mu_{\mathrm{N}}\right)$ & $\left\langle\beta^{2}\right\rangle^{1 / 2}$ & refs. \\
\hline $\mathrm{Pb}$ & 187 & $3 / 2^{-}$ & -1.126 & $<0.1$ & $13 / 2^{+}$ & -1.21 & $<0.1$ & {$[12]$} \\
& 189 & $3 / 2^{-}$ & -1.081 & $<0.1$ & $13 / 2^{+}$ & -1.19 & $<0.1$ & {$[12]$} \\
& 191 & $3 / 2^{-}$ & & & $13 / 2^{+}$ & -1.176 & 0.065 & {$[78]$} \\
$\mathrm{Hg}$ & 183 & $1 / 2^{-}$ & 0.524 & 0.27 & & & & {$[1]$} \\
& 185 & $1 / 2^{-}$ & 0.509 & 0.25 & $13 / 2^{+}$ & -1.017 & 0.15 & {$[1]$} \\
& 187 & $3 / 2^{-}$ & -0.594 & 0.15 & $13 / 2^{+}$ & -1.044 & 0.14 & {$[1]$} \\
& 179 & $1 / 2^{-}$ & 0.43 & 0.24 & & & & {$[6]$} \\
& 181 & $1 / 2^{-}$ & 0.48 & 0.24 & & & & {$[6]$} \\
& 183 & $1 / 2^{-}$ & 0.502 & 0.23 & $7 / 2^{-}$ & 0.78 & 0.24 & {$[6]$} \\
& 187 & $3 / 2^{-}$ & -0.399 & 0.19 & & & & {$[5,79]$} \\
& 189 & $3 / 21 / 2^{-}[510]^{(a)}$ & -0.32 & $\sim 0.18^{(b)}$ & & & & {$[23,80]$} \\
\hline
\end{tabular}

(a) Excited state.

(b) From $B(E 2)$ values of ${ }^{188,190}$ Os.

the $13 / 2^{+}$state in ${ }^{187} \mathrm{~Pb}$ at $E_{\mathrm{IS}}=33(13) \mathrm{keV}$ above the $3 / 2^{-}$ground state of ${ }^{187} \mathrm{~Pb}$. From this $E_{\mathrm{IS}}=33(13) \mathrm{keV}$ value in ${ }^{187} \mathrm{~Pb}$ we can deduce an energy location of the $13 / 2^{+}$state in ${ }^{183} \mathrm{Hg}$ at $E_{\mathrm{IS}}=219(18) \mathrm{keV}$. This latter value is in better agreement with the value estimated from the systematics shown in fig. 10 than that given by the $\alpha$ decay of the ${ }^{191} \mathrm{Po}$ study. Furthermore, the $7336 \mathrm{keV} \alpha$ particles from ${ }^{191} \mathrm{Po}$ which served to locate the $13 / 2^{+}$isomeric state in ${ }^{187} \mathrm{~Pb}$ has a rather small $\mathrm{HF}$ value $(\mathrm{HF}=21)$ for a $\Delta I=5 \alpha$ transition with parity change (see table 6). Therefore, we have adopted the $E_{\mathrm{IS}}=33(13) \mathrm{keV}$ value for the $13 / 2^{+}$state in ${ }^{187} \mathrm{~Pb}$ to determine the energy location of the $\left(13 / 2^{+}\right)$isomeric states in the $\alpha$-emitter chain starting with ${ }^{195} \mathrm{Rn}$. Thus, the $E_{\mathrm{IS}}$ values obtained are $219(18) \mathrm{keV}, 74(15) \mathrm{keV}$ and $93(21) \mathrm{keV}$ for the $13 / 2^{+}$isomeric states in ${ }^{183} \mathrm{Hg},{ }^{191} \mathrm{Po}$ and ${ }^{195} \mathrm{Rn}$, respectively.

It is well known that the main $\alpha$ decay of a nuclear state feeds preferably state with same spin value and same or close nuclear structure. Thus the results shown in fig. 9 and table 6 will be very useful to discuss the structure of some states of ${ }^{185} \mathrm{Hg}$ and ${ }^{189} \mathrm{~Pb}$ nuclei in the next section.

\section{Discussion}

Before discussing the nuclear structure of the states of the ${ }^{185} \mathrm{Hg}$ and ${ }^{189} \mathrm{~Pb}$ nuclei we have to recall what is known or well established in the neighbouring nuclei.

Important information on the isomeric and ground states of the $\mathrm{Pt}, \mathrm{Hg}$ and $\mathrm{Pb}$ nuclei has been provided by laser spectroscopy experiments. Thus, nuclear deformation parameters, $\beta$, have been deduced from isotope shift measurements and, from hyperfine spectra, nuclear angular momenta, $I$, have been confirmed or determined. Furthermore, nuclear moments are determined from hyperfine spectra, the nuclear magnetic moments, $\mu$, inform us about the structure of the nuclear states and, in some cases, the spectroscopic quadrupole moments, $Q \mathrm{~s}$, provide information on their nuclear shape. The $\beta, I$ and $\mu$ values determined in that way for the isomeric and ground states of the nuclei of interest for the discussion are listed in table 7 . All of the $1 / 2^{-}$ground states listed in table 7 have similar $\mu$ values around $+0.48 \mu_{\mathrm{N}}$. This is in agreement with the $1 / 2^{-}[521]$ nuclear structure attributed to these ground states.

In their isomeric and ground states, the neutrondeficient semi-magical ${ }^{187,189,191} \mathrm{~Pb}$ nuclei have a quasispherical shape since their $\beta$ values are smaller than 0.1 (see table 7 ). The $13 / 2^{+}$isomeric states of the $\mathrm{Pb}$ and $\mathrm{Hg}$ nuclei correspond to a neutron in the $i_{13 / 2}$ sub-shell, their $\mu$ values are similar and well reproduced by the theoretical calculations we have performed for spherical or weakly deformed prolate or oblate nuclear shape provided that the spin gyromagnetic factor used, $g_{\mathrm{s}}$, is increased relatively to that of a free neutron, $g_{\text {sfree }}=-3.8$, to take into account polarization effects in nuclear surroundings. For weakly deformed nuclei, we have calculated the $\mu$ values using the semi-microscopic axial-rotor +1 quasi-particle coupling model [81-83]. The $\mu$ values obtained for the ${ }^{189} \mathrm{~Pb} 13 / 2^{+}$ isomeric state using $g_{\mathrm{s}}=0.6 g_{\text {sfree }}$ are: $\mu=-1.15 \mu_{\mathrm{N}}$ for spherical shape, $\mu=-1.16 \mu_{\mathrm{N}}$ for weakly deformed prolate shape $(\beta=+0.08)$ and $\mu=-1.23 \mu_{\mathrm{N}}$ for weakly deformed oblate shape $(\beta=-0.07)$. All of these calculated values are close to the measured value $\mu=-1.19 \mu_{\mathrm{N}}$.

On the other hand, the $\mu$ values of the $3 / 2^{-}$ground states of the ${ }^{187,189} \mathrm{~Pb},{ }^{187} \mathrm{Hg}$ and ${ }^{187} \mathrm{Pt}$ nuclei are all negative with values that increase rather quickly with the nuclear-deformation increase (see table 7). This is due to an increase of the configuration admixtures in the wave functions describing the $3 / 2^{-}$states. For spherical nuclear shape if the neutron occupied the only $\mathrm{p}_{3 / 2}$ sub-shell the $\mu$ value should be $\mu=-1.91 \mu_{\mathrm{N}}$ for $g_{\mathrm{s}}=g_{\text {sfree }}$ and $\mu=-1.15 \mu_{\mathrm{N}}$ for $g_{\mathrm{s}}=0.6 g_{\text {sfree }}$. For a weakly deformed 
prolate nuclear shape $(\beta=+0.08)$ the wave function of the $3 / 2^{-}$state of ${ }^{189} \mathrm{~Pb}$ in spherical basis includes components corresponding to the coupling of the particle states $\left(\mathrm{p}_{1 / 2}, \mathrm{p}_{3 / 2}, \mathrm{f}_{5 / 2}, \ldots\right)$ with the excited states of the core $\left(2^{+}, 4^{+}, \ldots\right)$. Thus, it becomes

$$
\begin{aligned}
\Phi= & 0.27\left(\mathrm{p}_{3 / 2}\right)+0.23\left(2^{+} \otimes \mathrm{p}_{1 / 2}\right) \\
& +0.13\left(2^{+} \otimes \mathrm{p}_{3 / 2}\right)+0.11\left(4^{+} \otimes \mathrm{f}_{5 / 2}\right)+\ldots,
\end{aligned}
$$

and the $\mu$ values calculated using $g_{\mathrm{R}}=Z / A$ are

and

$$
\begin{array}{ll}
\mu=-0.66 \mu_{\mathrm{N}} & \text { for } \quad g_{\mathrm{s}}=g_{\text {sfree }} \\
\mu=-0.22 \mu_{\mathrm{N}} & \text { for } \quad g_{\mathrm{s}}=0.6 g_{\text {sfree }}
\end{array}
$$

In the same way, for a weakly deformed oblate nuclear shape $(\beta=-0.07)$ the wave function of the $3 / 2^{-}$state of ${ }^{189} \mathrm{~Pb}$ becomes

$\Phi=0.53\left(\mathrm{p}_{3 / 2}\right)+0.27\left(2^{+} \otimes \mathrm{p}_{3 / 2}\right)+0.13\left(2^{+} \otimes \mathrm{f}_{5 / 2}\right)+\ldots$,

and the $\mu$ values calculated using the same $g_{\mathrm{R}}$ value are then

and

$$
\begin{array}{ll}
\mu=-0.81 \mu_{\mathrm{N}} & \text { for } \quad g_{\mathrm{s}}=g_{\text {sfree }} \\
\mu=-0.43 \mu_{\mathrm{N}} & \text { for } \quad g_{\mathrm{s}}=0.6 g_{\text {sfree }}
\end{array}
$$

Therefore, for the $3 / 2^{-}$ground state of the ${ }^{189} \mathrm{~Pb}$ nucleus the best agreement of the calculated $\mu$ value with that measured $\mu=-1.081 \mu_{\mathrm{N}}$ (see table 7 ) is obtained for a mainly $\mathrm{p}_{3 / 2}$ configuration and a nuclear spherical shape.

The nuclear shape of the $3 / 2^{-}$ground states of the weakly deformed ${ }^{187,189,191} \mathrm{Pt}$ and ${ }^{187,189,191,193} \mathrm{Hg}$ nuclei has been a much debated question. It has been shown that only the $3 / 21 / 2^{-}[510]$ Nilsson state corresponding to a prolate shape could explain the negative sign of both the $Q_{\mathrm{s}}$ and $\mu$ experimental values of these $\mathrm{Pt}$ and $\mathrm{Hg} 3 / 2^{-}$ ground states $[79,83]$. The $\mu$ value of the $3 / 2^{-}$ground state of the ${ }^{187} \mathrm{Pt}$ nucleus is slightly smaller than that measured for the $3 / 21 / 2^{-}$[510] Nilsson state known in ${ }^{183}$ Os [23]. More recently, results obtained on the excited states of ${ }^{187} \mathrm{Pt}$ from in-beam experiments have confirmed the identification of the $3 / 2^{-}$ground state of the ${ }^{187} \mathrm{Pt}$ nucleus as mainly the $3 / 21 / 2^{-}[510]$ Nilsson state corresponding to a prolate nuclear shape [84]. In a spherical basis, the main components of the wave function of the $3 / 21 / 2^{-}[510]$ state obviously correspond to the coupling of the $2^{+}$state of the core with the $\mathrm{f}_{5 / 2}$ and $\mathrm{p}_{3 / 2}$ particle states. Thus, the nuclear structure of the $3 / 2^{-}$ground states of the ${ }^{187,189} \mathrm{~Pb},{ }^{187} \mathrm{Hg}$ and ${ }^{187} \mathrm{Pt}$ nuclei varies rather slowly with the deformation increase, which explains the increase of the $\mu$ value of the $3 / 2^{-}$ground state from neutron-deficient $\mathrm{Pb}$ to neutron-deficient $\mathrm{Pt}$ nuclei (see table 7 ).

Therefore, we know that the $3 / 2^{-}$ground states of ${ }^{187,189} \mathrm{~Pb}$ and ${ }^{187} \mathrm{Hg}$ have similar nuclear structure from their measured magnetic moments. In fig. 9 and table 6 we can see that the hindrance factors of the $\alpha$ transitions between the $3 / 2^{-}$ground states ${ }^{195,197,199} \mathrm{Rn} \rightarrow{ }^{191,193,195} \mathrm{Po} \rightarrow{ }^{187,189,191} \mathrm{~Pb}$ and ${ }^{191} \mathrm{~Pb} \rightarrow{ }^{187} \mathrm{Hg}$ are small, $0.46 \leq \mathrm{HF} \leq 4$, these favoured $\alpha$ transitions confirm that the $3 / 2^{-}$ground states of these $\mathrm{Rn}, \mathrm{Po}, \mathrm{Pb}$ and ${ }^{187} \mathrm{Hg}$ nuclei have also similar nuclear structure. The $3 / 2^{-}$ground state of the ${ }^{187} \mathrm{~Pb} \mathrm{nu}-$ cleus preferably decays towards the $275 \mathrm{keV}$ level of the ${ }^{183} \mathrm{Hg}$ nucleus, $\mathrm{HF}=2.2$, which strongly suggests that the $275 \mathrm{keV}$ level has a spin value $I=3 / 2^{-}$and a structure close to that of the $3 / 2^{-}$ground state of ${ }^{187,189,191} \mathrm{~Pb}$, ${ }^{187} \mathrm{Hg},{ }^{191,193,195} \mathrm{Po}$ and ${ }^{195,197,199} \mathrm{Rn}$ nuclei. In ${ }^{185} \mathrm{Hg}$, it is the $26 \mathrm{keV}$ level that has a structure close to that of the $3 / 2^{-}$ground state of the ${ }^{189} \mathrm{~Pb}$ nucleus since the $\alpha$ decay of the $3 / 2^{-}$ground state of ${ }^{189} \mathrm{~Pb}$ is more favoured to the $26 \mathrm{keV}$ level than to the $174 \mathrm{keV}$ level in the ${ }^{185} \mathrm{Hg}$ nucleus. The $174 \mathrm{keV}$ level of ${ }^{185} \mathrm{Hg}$ and the $67 \mathrm{keV}$ level of ${ }^{183} \mathrm{Hg}$ probably have a structure that differs from that of the $3 / 2^{-}$ground states of the $\mathrm{Pb}, \mathrm{Po}$ and $\mathrm{Rn}$ nuclei. However, it is very probable that these 275, 67, 26 and $174 \mathrm{keV}$ states correspond to a weak nuclear deformation of the ${ }^{183,185} \mathrm{Hg}$ nuclei.

From the $\mu$ values, we know that the structure of the $13 / 2$ isomeric states of the ${ }^{187,189,191} \mathrm{~Pb}$ and ${ }^{185,187} \mathrm{Hg} \mathrm{nu}-$ clei have a similar structure. The small hindrance factors, $0.9 \leq \mathrm{HF} \leq 3.4$ determined for the $\alpha$ decay between the $13 / 2^{+}$isomeric levels ${ }^{197,199} \mathrm{Rn} \rightarrow{ }^{193,195} \mathrm{Po}$, ${ }^{193,195} \mathrm{Po} \rightarrow{ }^{189,191} \mathrm{~Pb},{ }^{189} \mathrm{~Pb} \rightarrow{ }^{185} \mathrm{Hg}$ and ${ }^{187} \mathrm{~Pb} \rightarrow{ }^{183} \mathrm{Hg}$ indicate similar structure for these $13 / 2^{+}$levels with a probable quasi-spherical nuclear shape. On the other hand, the structure of the $\left(13 / 2^{+}\right)$isomeric state of the ${ }^{191}$ Po nucleus probably differs from that of the $13 / 2^{+}$isomeric states of these $\mathrm{Pb}$ nuclei since the hindrance factor of the $\alpha$ decay ${ }^{191} \mathrm{Po} \rightarrow{ }^{187} \mathrm{~Pb}$ (first $13 / 2^{+}$) is rather high, $\mathrm{HF}=70$. It is rather close to that of both the second $\left(13 / 2^{+}\right)$level of the ${ }^{187} \mathrm{~Pb}$ nucleus and $\left(13 / 2^{+}\right)$ isomeric state of the ${ }^{195} \mathrm{Rn}$ nucleus. It is worth noting that, from different theoretical approaches, an increase of the nuclear deformation has been predicted to arise in the neutron-deficient even-even Po. For example, May et al. [85] predict this deformation increase between ${ }^{190} \mathrm{Po}$ $(\beta=0.21)$ and ${ }^{188} \mathrm{Po}(\beta=0.28)$ and more recently, Delaroche et al. $[86]$ predict it between ${ }^{192} \mathrm{Po}(\beta=0.21)$ and ${ }^{190} \mathrm{Po}(\beta=0.29)$. Therefore, the structure change observed for the isomeric state between ${ }^{193} \mathrm{Po}$ and ${ }^{191} \mathrm{Po}$ indicates that the isomeric states in ${ }^{191} \mathrm{Po}$ and ${ }^{195} \mathrm{Rn}$ could correspond to a well-deformed prolate nuclear shape. In that case the two isomeric states would probably have a spin value that differs from the $13 / 2$ proposed in the literature.

\section{Conclusion}

The study of the ${ }^{185} \mathrm{Tl}$ decay performed in this work has served to identify about fifty $\gamma$-rays belonging to the $\beta^{+} / \mathrm{EC}$ decay of the $1 / 2^{+}$ground state of the ${ }^{185} \mathrm{Tl}$ nucleus towards levels of the ${ }^{185} \mathrm{Hg}$ nucleus. It has also confirmed that the $9 / 2^{-}$isomeric state of ${ }^{185} \mathrm{Tl}$ decays by a cascade of two isomeric transitions (fig. 2) whereas its $\beta^{+} / \mathrm{EC}$ decay was not observed. Furthermore, for the first time, a partial level scheme of low-spin levels $(I<9 / 2)$ of the ${ }^{185} \mathrm{Hg}$ nucleus has been built. 
Conversion electron lines of very low-energy transitions $8<E<36 \mathrm{keV}$ were observed for the first time thanks to measurements performed using the VLECED setup. The electron data have been obtained for six transitions, four in ${ }^{185} \mathrm{Au}$ and two in ${ }^{185} \mathrm{Hg}$. The analysis of the high energy resolution electron spectrum using an internal calibration has allowed us to precisely determine the energies of one transition in ${ }^{185} \mathrm{Au}$ and two of the three isomeric transitions of ${ }^{185} \mathrm{Hg}$. Thus, the energy location of the $13 / 2^{+}$isomeric state of ${ }^{185} \mathrm{Hg}$ has been determined to be $E_{\mathrm{is}}=103.7(4) \mathrm{keV}$. By combining the known $\alpha$ decay results of the ${ }^{185} \mathrm{Hg}$ nucleus with the well-known level scheme of the ${ }^{181} \mathrm{Pt}$ nucleus we have estimated an independent value for the excitation energy of the $13 / 2^{+}$ isomeric state in ${ }^{185} \mathrm{Hg}, E_{\text {is }}=94(13) \mathrm{keV}$. Both values are in agreement. Our value $E_{\text {is }}=103.7(4) \mathrm{keV}$ would be also in reasonable agreement with the value deduced from the ISOLTRAP experiment [35] provided an unexpected systematic error of $20 \mathrm{keV}$ is added to the statistic error, which would give $E_{\text {is }}=120(21) \mathrm{keV}$ instead of $E_{\text {is }}=120(5) \mathrm{keV}$.

The origin of the three $\alpha$ lines emitted from the two ${ }^{189} \mathrm{~Pb}$ isomers has been unambiguously identified from the hyperfine spectrum observed for each $\alpha$ line. This, combined with the $\alpha-\gamma$ coincidence measurement, the identification of the $\gamma$-rays from the $\beta^{+} / \mathrm{EC}$ decay of the $1 / 2^{+}$ ground state of the ${ }^{185} \mathrm{Tl}$ nucleus and the energy location of the $13 / 2^{+}$isomeric state in ${ }^{185} \mathrm{Hg}$ has allowed us to locate the $13 / 2^{+}$isomeric state at $40(4) \mathrm{keV}$ above the $3 / 2^{-}$ground state of the ${ }^{189} \mathrm{~Pb}$ nucleus. Furthermore, using known $\alpha$-decay data, the $13 / 2^{+}$isomeric states have been located at 95(7) $\mathrm{keV}$ and 194(12) $\mathrm{keV}$ above the $3 / 2^{-}$ ground states of the ${ }^{193} \mathrm{Po}$ and ${ }^{197} \mathrm{Rn}$ nuclei, respectively.

The comparison of the properties of the nuclei of the three $\alpha$-emitter chains starting with the ${ }^{195,197,199} \mathrm{Rn} n u-$ clei strongly suggests that the $3 / 2^{-}$excited states at $26 \mathrm{keV}$ in ${ }^{185} \mathrm{Hg}$ and at $275 \mathrm{keV}$ in ${ }^{183} \mathrm{Hg}$ have a nuclear structure similar to that (mainly $\mathrm{p}_{3 / 2}$ ) of the $3 / 2^{-}$ ground states of the ${ }^{187} \mathrm{Hg},{ }^{187,189,191} \mathrm{~Pb},{ }^{191,193,195} \mathrm{Po}$ and ${ }_{195,197,199} \mathrm{Rn}$ nuclei that have spherical or weakly deformed prolate shape. In the same way, the nuclear structure of the $13 / 2^{+}$isomeric states of the ${ }^{191} \mathrm{Po}$ and ${ }^{195} \mathrm{Rn}$ nuclei that appears to be similar to that of the second $13 / 2^{+}$ state of ${ }^{187} \mathrm{~Pb}$, differs from that of the other $13 / 2^{+}$isomeric states that correspond to a $i_{13 / 2}$ structure with quasi-spherical nuclear shape. The structure change of the isomeric state observed between ${ }^{193} \mathrm{Po}$ and ${ }^{191} \mathrm{Po}$ could be due to a large increase of the nuclear deformation for the isomeric state between ${ }^{193} \mathrm{Po}$ and ${ }^{191} \mathrm{Po}$.

We acknowledge support from the Spanish MINECO through projects FPA2010-17142 and CPAN CSD-2007-00042.

Open Access This is an open access article distributed under the terms of the Creative Commons Attribution License (http://creativecommons.org/licenses/by/3.0), which permits unrestricted use, distribution, and reproduction in any medium, provided the original work is properly cited.

\section{References}

1. G. Ulm et al., Z. Phys. A 325, 247 (1986) and references therein.

2. R. Béraud et al., Nucl. Phys. A 284, 221 (1977) and references therein.

3. K. Wallmeroth et al., Nucl. Phys. A 493, 224 (1989).

4. G. Savard et al., Nucl. Phys. A 512, 241 (1990).

5. T. Hilberath et al., Z. Phys. A 342, 1 (1992).

6. F. Le Blanc et al., Phys. Rev. C 60, 054310 (1999).

7. D. Verney et al., Eur. Phys. J. A 30, 489 (2006).

8. K. Heyde, P. van Isacker, M. Waroquier, J.L. Wood, R.A. Meyer, Phys. Rep. 102, 291 (1983) and references therein.

9. J.L. Wood, K. Heyde, W. Nazarewicz, M. Huyse, P. Van Duppen, Phys. Rep. 215, 101 (1992) and references therein.

10. K. Heyde, J.L. Wood, Rev. Mod. Phys. 83, 1467 (2011) and references therein.

11. H. de Witte et al., Phys. Rev. Lett. 98, 112502 (2007).

12. M. Seliverstov et al., Eur. Phys. J. A 41, 315 (2009).

13. P. Kilcher et al., Nucl. Instrum. Methods A 274, 485 (1989).

14. P. Kilcher et al., AIP Conf. Proc. 164, 517 (1987).

15. G.W. Grüter, B. Jonson, O.B. Nielsen, 3rd International Conference on Nuclei far from Stability, Cargèse, June 1976, Proc. CERN 76-13, 428 (1976).

16. M.J.A. de Voigt et al., Nucl. Phys. A 507, 447 (1990).

17. J. Sauvage et al., Nucl. Phys. A 540, 83 (1992).

18. E. Kugler et al., Nucl. Instrum. Methods B 70, 41 (1992).

19. S. Du, O. Hubert, J. Le Bris, R. Sellem, IPNO Report (1998-1999) Technical Activities, p. 110.

20. J. Le Bris et al., Rapport interne IPNO 06-03 (English version).

21. J. Le Bris et al., Rapport interne IPNO 05-04 (French version).

22. A.G. Schmidt et al., Phys. Lett. B 66, 133 (1977).

23. Richard B. Firestone, Virginia S. Shirley, Table of Isotopes, 8th edition (John Wiley \& Sons Inc., New York, 1996).

24. C. Bourgeois, P. Kilcher, B. Roussière, J. SauvageLetessier, M.G. Porquet, Nucl. Phys. A 386, 308 (1982).

25. P. Paris et al., Nucl. Instrum. Methods 186, 91 (1981).

26. J.C. Putaux et al., Nucl. Instrum. Methods 186, 321 (1981).

27. J. Sauvage et al., Proc. TRIUMF-ISOL Workshop, Mont Gabriel, Québec, Canada, TRI-84-1 (1984) p. 161.

28. B. Roussière et al., Nucl. Phys. A 643, 331 (1998).

29. F.P. Larkins, At. Data Nucl. Data Tables 20, 311 (1977).

30. M.H. Chen, B. Crasemann, H. Mark, At. Data Nucl. Data Tables 24, 13 (1979).

31. P.G. Hansen et al., Nucl. Phys. A 148, 249 (1970).

32. E. Hagberg, P.G. Hansen, P. Hornshøj, B. Jonson, S. Mattsson, P. Tidemand-Petersson, Nucl. Phys. A 318, 29 (1979).

33. S.-C. Wu, Nucl. Data Sheets 106, 367 (2005).

34. S.-C. Wu, Nucl. Data Sheets 106, 619 (2005).

35. S. Schwarz et al., Nucl. Phys. A 693, 533 (2001).

36. J. Lettry et al., Rev. Sci. Instrum. 69, 761 (1998).

37. U. Köster et al., Nucl. Instrum. Methods B 204, 347 (2003).

38. R. Dissert, H. Friedmann, M. Klipfel, A. Krauth, R. Limbach, G. Walter, CRN report (1990) ISBN 0755-3404, p. 156.

39. J. Sauvage et al., Eur. Phys. J. A 39, 33 (2009). 
40. H. Gauvin, Y. Le Beyec, M. Lefort, N.T. Porile, Phys. Rev. Lett. 29, 958 (1972).

41. P. Hornshøj et al., Nucl. Phys. A 230, 365 (1974).

42. J.O. Rasmussen, alpha-, beta- and gamma-ray spectroscopy, edited by Kai Siegbahn, Vol. 1 (North Holland Publishing Company, Amsterdam, 1965) Ch. XI, p. 701.

43. Zhou Chumei, Nucl. Data Sheets 86, 645 (1999).

44. C. Di Rienzo et al., Phys. Rev. C 21, 2101 (1980).

45. F. Calaprice, G.T. Ewan, Phys. Rev. C 30, 1671 (1984).

46. H.E. Enge et al., Phys. Rev. C 24, 298 (1981).

47. J. Wauters et al., Phys. Rev. C 47, 1447 (1993).

48. E. Achterberg et al., Nucl. Data Sheets 107, 1 (2006).

49. T. Enqvist et al., Z. Phys. A 354, 9 (1996).

50. V.R. Vanin et al., Nucl. Data Sheets 108, 2393 (2007).

51. H. Kettunen et al., Phys. Rev. C 63, 044315 (2001).

52. T.E. Cocolios et al., J. Phys. G Nucl. Part. Phys. 37, 125103 (2010) and references therein.

53. A.N. Andreyev et al., AIP Conf. Proc. 495, 121 (1999).

54. S.-C. Wu, H. Niu, Nucl. Data Sheets 100, 1 (2003).

55. S. Della Negra, B. Lagarde, Y. Le Beyec, J. Phys. Lett. 38, L393 (1977).

56. M.E. Leino, S. Yashita, A. Ghiorso, Phys. Rev. C 24, 2370 (1981).

57. M.S. Basunia, Nucl. Data Sheets 110, 299 (2009).

58. J.C. Batchelder et al., Phys. Rev. C 55, R 2142 (1997).

59. A.N. Andreyev et al., Phys. Rev. Lett. 82, 1819 (1999).

60. A.N. Andreyev et al., Phys. Rev. C 66, 014313 (2002).

61. Y. Le Beyec, M. Lefort, J. Livet, N.T. Porile, Phys. Rev. C 9, 1091 (1974).

62. Coral M. Baglin, Nucl. Data Sheets 91, 117 (2009).
63. P. Misaelides et al., Z. Phys. A 301, 199 (1981).

64. Coral M. Baglin, Nucl. Data Sheets 110, 265 (2009).

65. M.I. Macias-Marques et al., Nucl. Phys. A 427, 205 (1984).

66. M.G. Desthuilliers et al., Nucl. Phys. A 313, 221 (1979).

67. W.F. Mueller et al., Phys. Rev. C 59, 2009 (1999).

68. G.J. Lane et al., Nucl. Phys. A 589, 129 (1995).

69. D.T. Shi et al., Phys. Rev. C 51, 1720 (1995).

70. B. Roussière et al., Proceedings of the International Symposium on In-Beam Nuclear Spectroscopy, Debrecen, Hungary (1984).

71. F. Hannachi et al., Z. Phys. A 330, 15 (1988).

72. G.D. Dracoulis, C. Fahlander, A.P. Byrne, Nucl. Phys. A 401, 490 (1983).

73. A. Neskakis et al., Nucl. Phys. A 261, 189 (1976).

74. B. Roussière et al., Z. Phys. A 351, 127 (1995).

75. B. Roussière, C. Bourgeois, P. Kilcher, J. Sauvage, M.G. Porquet, Nucl. Phys. A 504, 511 (1989).

76. J. Nyberg et al., Nucl. Phys. A 511, 92 (1990).

77. C. Weber et al., Phys. Lett. A 347, 81 (2005).

78. S.B. Dutta et al., Z. Phys. A 341, 39 (1991).

79. J. Sauvage et al., Hyperfine Interact. 129, 303 (2000).

80. S. Raman et al., At. Data Nucl. Data Tables 36, 26 (1987).

81. M. Meyer et al., Nucl. Phys. A 316, 93 (1979).

82. J. Libert et al., Phys. Rev. C 25, 582 (1982).

83. J. Sauvage et al., Phys. At. Nucl. 64, 1134 (2001).

84. D. Hojman et al., Eur. Phys. J. A 48, 83 (2012).

85. F.R. May, V.V. Pashkevich, S. Frauendorf, Phys. Lett. B 68, 113 (1977).

86. J.P. Delaroche et al., Phys. Rev. C 81, 014303 (2010) and http://www-phynu.cea.fr/HFB-5DCH-table.htm. 